\title{
Credit, Misallocation and Productivity Growth: A Disaggregated Analysis*
}

\author{
Felipe Meza \\ CAIE and Dept. of Economics \\ ITAM
}

\author{
Sangeeta Pratap \\ Hunter College \& Graduate Center \\ City University of New York
}

\author{
Carlos Urrutia \\ CIE and Dept. of Economics
}

ITAM

September 2, 2016

\begin{abstract}
We study the effect of credit conditions on the allocation of inputs, and their implications for aggregate TFP growth. For this, we build a new dataset for Mexican manufacturing merging real and financial data at the 4-digit industrial sector level. Using a simple misallocation framework, we find that changes in allocative efficiency account for 75 percent of aggregate TFP variability. We then construct a model of firm behavior with working capital constraints and borrowing limits which generate sub-optimal use of inputs, and calibrate it to our data. We find that the model accounts for 56 percent of the observed variability in efficiency. An important conclusion is that sectoral heterogeneity in credit conditions is key in accounting for efficiency gains. Despite overall credit stagnation, better credit and lower interest rates to distorted sectors contributed substantially to the recovery from the 2009 recession, suggesting a plausible mechanism for credit-less recoveries.
\end{abstract}

Keywords: Misallocation; Total Factor Productivity; Financial Frictions; Interest Rates

\footnotetext{
${ }^{*}$ We are grateful for financial support from the Fundacion de Estudios Financieros. We thank the Instituto Nacional de Estadistica, Geografia e Informatica (INEGI), and especially Gerardo Leyva and Natalia Volkow for their help with the survey on manufacturing establishments. We are indebted to the Comision Nacional Bancaria y de Valores for making information on bank loans available to us. We also thank Ana Maria Aguilar and Othon Martinez at Banco de Mexico for their support. All data provided to us were anonymized by the respective source. Comments from Ana Maria Aguilar, Hugo Hopenhayn, Pete Klenow, Diego Restuccia, Felipe Saffie, Mark Wright, Julieta Caunedo and participants at the Society for Economic Dynamics Meetings in Toronto, the North American Summer Meetings of the Econometric Society in Minneapolis, the IDB Workshop on Misallocation, the ITAM-PIER Conference on Macroeconomics, and seminar participants at the Banco de Mexico and the IMF are gratefully acknowledged. Alonso de Gortari, Hoda Nouri Khajavi and Daniel Ramos provided outstanding research assistance. All errors are our own. Corresponding author: Sangeeta Pratap, Dept. of Economics, Hunter College and Graduate Center, City University of New York, 695 Park Ave, New York NY 10065. Email: sangeeta.pratap@hunter.cuny.edu
} 


\section{Introduction}

The relationship between output growth and total factor productivity is well established. The earliest calculations of Solow (1957) attributed only 12 percent of the growth in the United States between 1900 and 1949 to the accumulation of factors of production, and the remaining 88 percent to the "residual". Subsequent work enlarging the scope and range of these estimates reduced the size of the residual to about 50 percent (see for example Klenow and Rodriguez Clare 1997), however the contribution of TFP to growth is undeniable. Movements in TFP have played an important role in recent growth miracles in India (Bollard et al. 2013) and China (Dekle and Vandenbroucke 2010). The reverse has also been true, large drops in output during "sudden stops" have been accompanied by a corresponding fall in TFP (Calvo et al. 2006).

Recent studies have highlighted the role of input misallocation as an important factor behind TFP changes in aggregate models. Pratap and Urrutia (2012) show that financial frictions can propagate interest rate shocks into measured TFP fluctuations by distorting the use of inputs in the economy. Benjamin and Meza (2009) analyze the real effects of Korea's 1997 crisis and find that a reallocation of resources towards low productivity sectors at this time generates a fall in TFP. A related strand of literature seeks to explain the differences in TFP levels across countries by emphasizing the role of firm-specific distortions, i.e. implicit taxes, barriers and constraints which result in a sub-optimal allocation of resources and lower TFP levels (see, for instance, Restuccia and Rogerson 2008, Hsieh and Klenow 2009, Bartelsman et al. 2013). Sandleris and Wright (2014) use the same insights to understand changes in TFP over time, using firm level data from Argentina around the 2001 crisis. Oberfield (2013) and Chen and Irarrazabal (2015) perform similar analyses for the Chilean manufacturing sector after the 1982 debt crisis. These papers however, do not quantitatively examine the economic forces behind the distortions observed in the data.

The goal of this paper is to understand the role of credit and financial frictions in accounting for the misallocation of resources and the changes in TFP over time. As in Pratap and Urrutia (2012), we focus on financial frictions that distort firms' decisions to purchase inputs. However, as in the literature reviewed in the previous paragraph, we analyze the relation between credit and distortions at the micro level, instead of the aggregate macro level. In this sense, our work relates to Buera and Moll (2015), who extend the business cycle accounting methodology to economies with heterogeneous firms and show that credit shocks and financial frictions can be mapped into measured TFP and other aggregate wedges or distortions. ${ }^{1}$

An important contribution of our work is the construction of a novel data set linking manufacturing activity in Mexico with credit flows and interest rates at a disaggregated level from 2003 to 2012. This is a particularly interesting time frame to study, since it includes the period of rapid growth of 2003-08, the economic crisis of 2008-09 and the subsequent recovery. We have detailed data on output, input expenditures, investment, capital stock, new credit flows and interest rates for 82 sectors of economic activity. The data allows us to construct measures of input distortions for each sector and year and, in the context of a simple static framework, to map the evolution of these distortions into a measure of allocative efficiency that affects aggregate TFP over time. Moreover, the availability of credit data makes possible to investigate the extent to which the efficiency of input allocation can be explained by financial factors.

\footnotetext{
${ }^{1}$ This follows from the work of Chari, Kehoe and McGrattan (2007) who introduce the methodology of business cycle accounting as a way of inferring the aggregate levels of distortions that an economy faces, and their evolution over time. The idea is to infer these distortions from the deviations ("wedges") from the optimality conditions of a standard neoclassical model. For example, the labor wedge is defined as the ratio between the marginal rate of substitution of consumption for leisure and the marginal product of labor, which should be equal to 1 in an undistorted economy.
} 
A simple accounting exercise using only data on output and input expenditures by sector shows that efficiency gains accounted for 75 percent of aggregate TFP variability over time. ${ }^{2}$ This number includes significant differences across subperiods. More than half the pre-crisis growth and three quarters of the recovery came from improvements in efficiency. The accounting framework also suggests that the identity of the sectors which experience the improvement in distortions is important. Improvements in allocative efficiency are possible only if highly distorted sectors are able to reduce their distortions.

We then build a static model that maps financial frictions into distortions to the use of inputs. Firms face a working capital constraint and a borrowing limit. The former implies that firms have to finance their variable input purchases with bank credit or the more expensive trade credit, while the latter dictates the amount of bank credit available to firms. Taken together, the constraints dictate the availability and costs of credit which, in turn, influence input use and determine the degree of allocative efficiency. We calibrate the borrowing constraint for each sector from the data and feed it into the model, along with the observed interest rates. This allows us to assess the impact of the availability and cost of credit on misallocation and the evolution of TFP in the economy. Feeding the model with observed credit conditions, we find that the model accounts for 56 percent of the variability in allocative efficiency over time. In particular, it explains more than 60 percent of efficiency gains in the early expansion and almost 80 percent in the recovery.

Our results also emphasize the role of sectoral heterogeneity. More than half of the efficiency gains in the recovery can be attributed to the heterogeneity of changes in credit conditions. This suggests a potential mechanism by which "credit-less recoveries", as documented by Calvo et al. (2006) may occur. Low aggregate levels of credit after the recession mask substantial sectoral heterogeneity in credit and interest rates. If credit and/or lower interest rates are available to highly distorted sectors, aggregate TFP and output will respond positively. In other words, the destination of credit matters as much as its aggregate quantity.

Compared to the recent work of Gilchrist et al. (2013) and Midrigan and Xu (2014), both of which find small losses to TFP from financial frictions, we study a different dimension of the relationship between credit and productivity: the link to TFP growth. Using data on borrowing costs on market debt of publicly traded companies, Gilchrist et al. (2013) find that resource misallocation accounts for about 3.5 percent of TFP losses in the U.S. economy in the 2000-2010 period. Midrigan and Xu (2014) construct a model of firm dynamics with borrowing constraints and find that misallocation accounts for 5 to 10 percent of the aggregate TFP loss using micro data from Korea and Colombia. Both studies focus on differences in TFP levels with the ultimate goal of explaining differences in productivities across countries. Our goal is different, in that we study how changes in credit conditions affect TFP growth, not its level. ${ }^{3}$

To provide a comparison with their results, we calculate the static TFP loss due to misallocation in our model to be 8.5 percent, an estimate in the upper range of Midrigan and Xu (2014) and more than double that of Gilchrist et al. (2013). A difference between our paper and Gilchrist et al. (2013) is that they focus on publicly traded firms with a substantially lower dispersion in interest rates than in our sample. ${ }^{4}$

\footnotetext{
${ }^{2}$ This exercise can be seen as an extension of the analysis in Hsieh and Klenow (2009), with two important differences. First, we explicitly include intermediate goods in the analysis. Second, and more importantly, our focus is on changes in TFP over time, rather than the comparison of TFP levels across countries.

${ }^{3}$ With a different methodological approach, some recent papers find important effects of credit conditions on efficiency gains in Japan (Kwon et al., 2015) and in the U.S. and Canada (Estevao and Severo, 2014).

${ }^{4}$ Gilchrist et al. (2013) report an average real interest rate of 2.4 percent with a standard deviation of 1.7 across firms (see their Table 2). In our sample, the mean interest rate is about the same (2.2), but the standard deviation across sectors is 2.8 . Table 1 provides further details of our data.
} 
Moreover, they assume no credit constraints, which play an important role in our model. In Midrigan and $\mathrm{Xu}$ (2014), the ability of firms to accumulate capital allows them to undo the effects of borrowing constraints over time. We do not have this dynamic mechanism in our setup, where the assumption of constant returns to scale abstracts from any issues related with the optimal size of firms.

The paper is organized as follows. In Section 2 we describe the data used to analyze the relationship between economic activity and credit and describe both aggregate and sectoral statistics. Section 3 sets out an analytical framework to identify sectoral distortions and account for aggregate TFP changes through efficiency gains. We apply this methodology to our dataset for Mexican manufacturing and find that efficiency gains play a large role in TFP fluctuations. Section 4 presents a static model with financial frictions linking credit variables and sectoral distortions. We calibrate and simulate the model subject to changes in credit conditions taken from the data and discuss its implications for distortions and efficiency gains. Section 5 performs some counterfactual experiments to understand the main mechanisms in our model. The last section concludes.

\section{Data and Stylized Facts}

As mentioned above, a major contribution of our paper is the construction of a new data set linking output, employment and productivity with credit flows and interest rates at the 4-digit sector level for Mexican manufacturing. In this section we describe our primary sources and indicate how we use them to assemble the data set. We also present both aggregate and sector level statistics.

\subsection{Dataset Construction}

We have two main data sources: The first is the annual industrial survey (EIA for its acronym in Spanish) collected by the Mexican statistical agency INEGI. The second source is the R04C credit registry maintained by the banking regulatory authority, the Comision Nacional Bancaria y de Valores. Confidentiality restrictions prohibit us from analyzing the data at the establishment or loan level. Consequently, we work at the lowest level of aggregation currently feasible, the 4-digit industry level, following the 2007 North American Industrial Classification System (NAICS). Appendix A.1 provides a detailed description of the variables used from both datasets and the strategy used to match real and financial variables at the sectoral level.

The EIA dataset is a representative sample of nearly 7000 manufacturing establishments. We have information on all 86 4-digit sectors and 231 subsectors at the 6 -digit level. Four sectors had missing information for some years, ${ }^{5}$ so our analysis uses 82 -digit manufacturing sectors. We use data on gross output and expenditure on intermediate goods to construct measures of value added. The labor input is measured as the number of people hired directly and indirectly by the establishment. The capital input is constructed using the perpetual inventory method, using information on investment. All nominal variables, with the exception of intermediate goods, are deflated by the producer price index for manufacturing published by INEGI. Expenditures in intermediate goods are deflated by an intermediate goods price index.

The R04C dataset includes information on the universe of loans by commercial banks to firms. We construct a measure of credit flow by looking at the debt outstanding on all new loans (i.e. loans with dates of disbursement in the month in which the data is collected) in a particular sector. This gives us information

\footnotetext{
${ }^{5}$ Aggregates of subsectors containing 4 or fewer firm-year observations were not provided to us in the interest of confidentiality.
} 


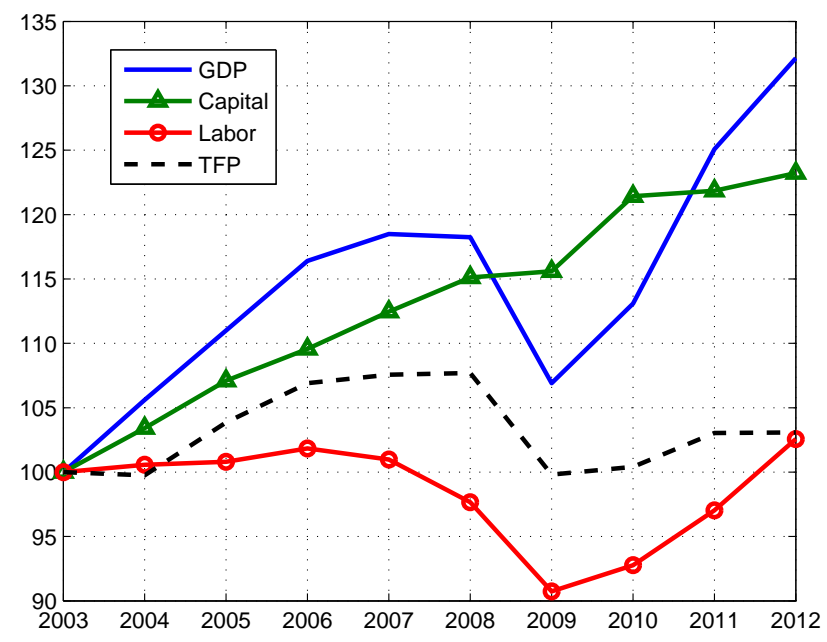

Figure 1: Value Added, Inputs and Total Factor Productivity (2003=100)

on how much credit was disbursed to each sector in each period. We focus on short term credit, defined as credit which matures in a period of 12 months or less, which accounts for about 85 percent of all bank credit to firms. ${ }^{6}$ Finally, we construct measures of the cost of credit by looking at average real interest rates paid by sector, weighted by the size of the loan in the total credit flow in the corresponding period, and deflated by the change in the producer price index for manufacturing.

\section{$2.2 \quad$ Aggregate Trends}

Our datasets overlap for the period 2003-2012. Figure 1 shows real manufacturing value added, capital and labor inputs from our sample, relative to the year 2003. Value added in manufacturing grew at an annual average rate of 2.5 percent between 2003 and 2008. The growth in employment was close to zero ${ }^{7}$, suggesting that growth in productivity was an important component of output growth in this period. This period of expansion came to a halt in 2009 as the international financial crisis hit Mexico. Manufacturing value added contracted by 11.5 percent, accompanied by a fall in labor input of about 7 percent. Investment also slowed down substantially, leading to a deceleration in the growth of capital. The recovery in output from 2010 onwards was strong, almost 4.5 percent per year.

The dotted line in Figure 1 shows the evolution of aggregate total factor productivity (TFP) in

\footnotetext{
${ }^{6}$ As we will see in later sections, we consider financial frictions which affect firms' working capital. This justifies our focus on short term credit. We also exclude revolving credit or lines of credit, which might not imply actual disbursements, as well as loan refinancing.

${ }^{7}$ This trend is confirmed by the National Survey of Occupation and Employment (ENOE for its acronym in Spanish). The employment in manufacturing series from the ENOE exhibits very similar behavior.
} 

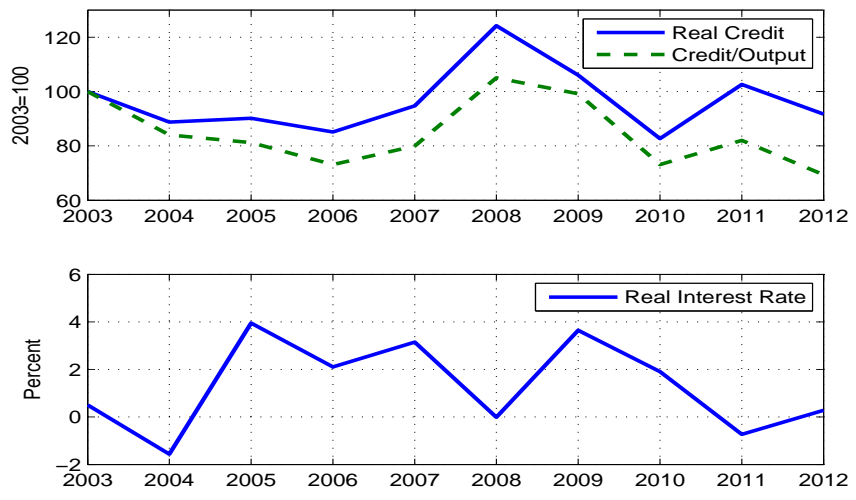

Figure 2: Real Credit Flow, Credit Intensity, and Average Real Interest Rate

manufacturing over the period. ${ }^{8}$ TFP increased between 2004 and 2008 at an average annual rate of about 1.5 percent, accounting for more than 60 percent of the growth in output. The fall in output in 2009 saw a corresponding decline in TFP of 7.3 percent. After the crisis we observe a modest recovery in TFP of about 1 percent per year. The main goal of our paper is to understand this behavior of aggregate TFP in manufacturing over time.

We now turn to financial variables. The first panel of Figure 2 shows the aggregate real flow of short term credit to the manufacturing sector, constructed as described above. The initial period of output expansion was not accompanied by an increase in credit, however, there was a short-lived credit boom form 2006 to 2008 with credit flows increasing by almost 30 percent in 2007-2008. The recession in 2009 saw a contraction in short term credit of about 16 percent. $^{9}$ Interestingly, aggregate credit did not recover along with output after the crisis. In other words, we observe a credit-less recovery.

While these changes in credit flows reflect both supply and demand factors, the behavior of the creditoutput ratio suggests that the supply of credit by banks has played a leading role. Credit intensity, measured as the ratio of credit flows to gross output, also shown in Figure 2, reveals that in the overall period changes in real credit were accompanied by similar changes in credit intensity. It seems reasonable to think that credit did not simply follow credit demand generated by the cyclical behavior of output, but that there is

\footnotetext{
${ }^{8}$ Assuming a Cobb Douglas production function, aggregate TFP is defined as
}

$$
A=\frac{Y}{K^{\alpha} L^{1-\alpha}}
$$

where $Y$ represents real value added and $K$ and $L$ measure aggregate inputs of capital and labor respectively. The aggregate labor share $1-\alpha$ is constructed as a weighted average of the labor share of income in each sector, weighted by its share in value added. For reasons elaborated in Section 3, these income shares are taken from the corresponding sectors in the U.S.

${ }^{9}$ Carabarin et al. (2015) show that in 2009 large firms substituted domestic credit by international debt issuance. Their evidence, however, is based on a small set of firms (53 for the entire period 2006-2014), mostly in the services sector. Moreover, this behavior pertains to medium-term debt. We abstract from this potentially interesting margin due to the lack of data availability, but our conjecture is that it is much less relevant for short run loans used to finance working capital in the typical manufacturing firm. 
an important supply factor involved.

Finally, the second panel of Figure 2 provides a measure of the average real interest rate for manufacturing activity, weighted by the share of credit flows to each sector. In general, interest rates move in the opposite direction as the flow of credit, providing further evidence for changes in the supply of credit. High (though fluctuating) interest rates in the period up to 2007 made borrowing more expensive on average. The boom in credit in 2008 was accompanied by a fall in the real interest rate of almost 3 percentage points. In the next year the contraction in output and credit in 2009 is correlated with a sharp increase in the interest rate back to 2005 levels. The recovery period was marked by low interest rates although, as mentioned above credit flows did not increase.

\subsection{Sectoral Heterogeneity}

It is well documented that significant heterogeneity exists in firms' access to and in the cost of credit (for the U.S. economy, see for instance Gertler and Gilchrist, 1994, and Gilchrist et al., 2013). Our disaggregated data for Mexican manufacturing also reveal a large variation in credit and interest rates as well as in real outcomes across sectors.

Table 1 shows some measures of dispersion of real and financial variables and describes how they are related to each other. For the rest of the paper, we will find it convenient to divide our time period into four subperiods. The first two periods are both periods of growth in output, accompanied by credit stagnation and credit growth respectively, the third is the recession and the last subperiod is the recovery from the financial crisis.

Gross output and value added vary substantially across sectors. The largest sectors produce more than 40 times the output and value added of the bottom tenth percentile. Short term credit and credit intensity also show similar patterns. While the average credit intensity was around 0.21 over the period, the $90 / 10$ ratio is over 25 .

Real interest rates fluctuated around an average of about 2 percent this period, rising to 3.5 percent during the recession, and dropping by two percentage points in the recovery. These relatively small aggregate movements mask substantial intersectoral variation: even in periods of relatively low interest rates, the highest real rates were almost 6 percentage points higher than the lowest. ${ }^{10}$

The bottom panel of the table shows correlations between real and financial variables. As we would expect, both credit and credit intensity are inversely related to interest rates. An exception is the 2008-2009 recession where credit was only available at higher rates. Larger sectors (measured in terms of output, value added or labor) have higher amounts of credit. These sectors also (mostly) seem to procure it at lower rates. An exception again is the recession, as well as 2003-2005, when credit was scarce.

\subsection{Reallocation Indices}

To supplement the summary statistics and correlations across time, we would also like to have a sense of the changes in credit conditions faced by each sector over time. To understand that we compute measures

\footnotetext{
${ }^{10}$ For some perspective on the magnitudes of the interest rates, the average real rate on 364-day Mexican Treasury Bills (CETES) over this entire period was 0.74 percent. The interest rates we observe therefore carry a significant risk premium on average. The premium is largest for 2009, when the 364-day Treasury Bill rate was 51 basis points. Comparisons using yields on 182-day or 91-day Treasury Bills are similar.
} 


\begin{tabular}{|c|c|c|c|c|c|}
\hline Yearly averages & 2003-05 & 2005-08 & 2008-09 & 2009-12 & 2003-12 \\
\hline \multicolumn{6}{|l|}{ Gross Output } \\
\hline Mean & 24.7 & 27.5 & 25.0 & 28.9 & 26.8 \\
\hline Std. Dev & 42.5 & 49.3 & 45.4 & 57.9 & 49.8 \\
\hline 90 th/10th & 42.0 & 45.9 & 48.5 & 50.6 & 49.7 \\
\hline \multicolumn{6}{|l|}{ Value Added } \\
\hline Mean & 10.0 & 10.8 & 9.85 & 10.6 & 10.4 \\
\hline Std. Dev & 15.6 & 17.0 & 15.9 & 17.1 & 16.5 \\
\hline 90 th/10th & 44.3 & 43.1 & 50.6 & 43.9 & 44.3 \\
\hline \multicolumn{6}{|l|}{ Credit } \\
\hline Mean & 2.51 & 2.74 & 2.86 & 2.49 & 2.61 \\
\hline Std. Dev & 4.49 & 5.08 & 4.08 & 3.39 & 4.34 \\
\hline 90 th/10th & 58.8 & 44.1 & 35.0 & 109.7 & 61.8 \\
\hline \multicolumn{6}{|l|}{ Credit Intensity } \\
\hline Mean & 0.19 & 0.22 & 0.26 & 0.20 & 0.21 \\
\hline Std. Dev & 0.23 & 0.23 & 0.35 & 0.30 & 0.28 \\
\hline 90 th/10th & 25.5 & 30.9 & 21.1 & 24.7 & 26.2 \\
\hline \multicolumn{6}{|l|}{ Real Interest Rates } \\
\hline Mean & 1.96 & 2.69 & 3.46 & 1.44 & 2.17 \\
\hline Std Dev & 4.08 & 1.90 & 1.46 & 2.02 & 2.81 \\
\hline 90th-10th & 8.28 & 4.44 & 3.19 & 5.38 & 6.32 \\
\hline \multicolumn{6}{|l|}{ Correlations } \\
\hline Credit Intensity, Interest Rate & -0.13 & -0.22 & 0.04 & -0.24 & -0.13 \\
\hline Credit, Interest Rate & -0.14 & -0.32 & 0.09 & -0.38 & -0.19 \\
\hline Credit, $L$ & 0.39 & 0.34 & 0.53 & 0.42 & 0.39 \\
\hline Credit, Output & 0.49 & 0.43 & 0.51 & 0.39 & 0.43 \\
\hline Credit, Value Added & 0.52 & 0.47 & 0.48 & 0.44 & 0.47 \\
\hline Interest Rate, $L$ & 0.02 & -0.07 & 0.12 & -0.19 & -0.04 \\
\hline Interest Rate, Output & 0.11 & -0.18 & -0.01 & -0.25 & -0.06 \\
\hline Interest Rate, Value Added & 0.09 & -0.17 & 0.02 & -0.22 & -0.05 \\
\hline
\end{tabular}

Note: The statistics are computed across all 82 sectors and averaged across years. Output, value added and credit are in thousands of million real pesos. 90th and 10th refer to the respective percentiles. Credit Intensity is measured as the credit to output ratio. Interest Rates are weighted averages of loan rates, weighted by the loan size.

Table 1: Summary Statistics for Real and Financial Variables - All Mexican Manufacturing Activity 


\begin{tabular}{|c|ccc|ccc|ccc|}
\hline & \multicolumn{3}{|c|}{ Credit } & \multicolumn{3}{c|}{ Credit/Output } & \multicolumn{3}{c|}{ Interest Rate } \\
& $C_{t t^{\prime}}$ & $D_{t t^{\prime}}$ & $R_{t t^{\prime}}$ & $C_{t t^{\prime}}$ & $D_{t t^{\prime}}$ & $R_{t t^{\prime}}$ & $C_{t t^{\prime}}$ & $D_{t t^{\prime}}$ & $R_{t t^{\prime}}$ \\
\hline \hline $2003-2005$ & 0.125 & 0.176 & 0.301 & 0.078 & 0.216 & 0.295 & 0.238 & 2.343 & 2.582 \\
$2005-2008$ & 0.184 & 0.078 & 0.263 & 0.214 & 0.068 & 0.282 & 0.084 & 0.583 & 0.668 \\
$2008-2009$ & 0.133 & 0.292 & 0.425 & 0.190 & 0.219 & 0.410 & 1.158 & 0.005 & 1.163 \\
$2009-2012$ & 0.158 & 0.206 & 0.363 & 0.150 & 0.245 & 0.395 & 0.172 & 0.390 & 0.563 \\
\hline
\end{tabular}

Table 2: Reallocation Indices

of reallocation of credit flows across sectors. Following Herrera et al. (2011) we construct a measure of reallocation across sectors based on gross labor flows measures proposed by Davis and Haltiwanger (1992). Consider $f_{i t}$, the credit flow to sector $i$ at time $t$, and define the growth of credit in a sector between time $t$ and $t^{\prime}$ as

$$
g_{i t}=\frac{f_{i t^{\prime}}-f_{i t}}{\left(f_{i t^{\prime}}+f_{i t}\right) / 2}
$$

Then we can define credit creation between time $t$ and $t^{\prime}$ as $C_{t t^{\prime}}$ and credit destruction in the same period as $D_{t t^{\prime}}$ as weighted averages of the positive and negative growth rates each period, where

$$
C_{t t^{\prime}}=\sum_{g_{i t} \geq 0} g_{i t}\left(\frac{\left(f_{i t^{\prime}}+f_{i t}\right) / 2}{\left(F_{t}^{\prime}+F_{t}\right) / 2}\right) \quad D_{t t^{\prime}}=\sum_{g_{i t}<0}\left|g_{i t}\right|\left(\frac{\left(f_{i t^{\prime}}+f_{i t}\right) / 2}{\left(F_{t}^{\prime}+F_{t}\right) / 2}\right)
$$

and $F_{t}=\sum_{i} f_{i t}$. The total reallocation is measured by the variable

$$
R_{t t^{\prime}}=C_{t t^{\prime}}+D_{t t^{\prime}}
$$

We also construct analogous indices for credit intensities and real interest rates. While we cannot talk about the "reallocation" of these two variables in a meaningful way, these numbers are useful to give us an idea of the magnitude of the increases (decreases) in the cost and availability of credit for those sectors for which each of these variables went up (down).

The left panel of Table 2 shows a significant reallocation of credit over the sample period. Overall credit stagnation does not imply a stagnation in credit in all sectors. As the last line of the table shows, in the recovery period, when overall credit growth was sluggish, the sectors where credit flows increased, saw a growth rate of 15.8 percent. Credit intensity for these sectors also increased in a similar magnitude. During the recession, an aggregate credit contraction of 16 percent was accompanied by a 13 percent increase in credit in some sectors, and a 30 percent decline in others. Interest rate movements were similarly heterogenous. The recovery of 2009-2012 saw a decline in interest rates of almost 40 percent in many sectors, while others saw an increase of about 17 percent. On the other hand, the recession was accopanied by an increase in the interest rate (of 115 percent) for almost all sectors.

In what follows, we explore the link between credit and productivity in greater detail, explicitly taking into account the substantial heterogeneity across sectors that we documented. Our analysis proceeds in two steps. First, in Section 3 we set up a framework that relates TFP movements to changes in the distortions in the use of inputs and the corresponding efficiency gains or losses. In Section 4 we construct a model which relates these distortions to the cost and availability of credit. Calibrating the model to the data and tracing the evolution of credit conditions through this period will give us a measure of how movements in productivity are related to credit conditions. 


\section{Misallocation and Efficiency Gains}

Consider a simple static model of multi-sector production with intermediate goods and sector specific distortions. These distortions introduce wedges between factor prices and marginal products. We derive an expression relating changes in aggregate TFP to the level of distortions in each sector and their growth rate, that we summarize as allocative efficiency gains. This simple framework is based on Hsieh and Klenow (2009). However, we start at the sectoral level, consider explicitly intermediate goods and focus on TFP changes over time, instead of productivity levels. Using our data, we perform an accounting exercise which reveals a large role for efficiency gains in explaining the evolution of TFP in Mexican manufacturing over time.

\subsection{A Simple Misallocation Framework}

The production structure consists of $n$ sectors, each of which is characterized by a representative firm operating under constant returns to scale and perfect competition. Firms produce (gross) output using capital, labor and intermediates according to the production function

$$
Y^{i}=A^{i}\left[\left(K^{i}\right)^{\alpha^{i}}\left(L^{i}\right)^{1-\alpha^{i}}\right]^{\varepsilon^{i}}\left(M^{i}\right)^{1-\varepsilon^{i}} \quad i \in\{1, \ldots, n\}
$$

The output of each sector is combined using a Cobb-Douglas aggregator to produce aggregate gross output

$$
Y^{g}=\prod_{i=1}^{n}\left(Y^{i}\right)^{\omega^{i}}
$$

which can be used to satisfy final demand $(Y)$ or to create intermediates $(M)$ at a linear transformation rate

$$
Y^{g}=Y+\phi M
$$

Summing across all sectors, we aggregate inputs as

$$
K=\sum_{i=1}^{n} K^{i} \quad L=\sum_{i=1}^{n} L^{i} \quad M=\sum_{i=1}^{n} M^{i}
$$

and define aggregate (value added) TFP as

$$
T F P=\frac{Y^{g}-\phi M}{K^{\alpha} L^{1-\alpha}}
$$

with aggregate factor shares constructed as weighted averages of sectoral factor shares $\varepsilon=\sum_{i=1}^{n} \omega^{i} \varepsilon^{i}$ and

$\alpha=\frac{\sum_{i=1}^{n} \omega^{i} \alpha^{i} \varepsilon^{i}}{\varepsilon}$. We maintain this production structure throughout the paper, in particular in the fully specified model with financial frictions discussed in the next section.

\subsubsection{Introducing Sector Specific Distortions}

The accounting exercise assumes that each sector faces three sector-specific distortions, which we model for simplicity, as wedges to capital, labor and intermediate goods purchases. In each period, the profits of sector $i$ representative firm are defined as

$$
\pi_{i} \equiv p_{i} Y^{i}-\theta_{K}^{i} r K^{i}-\theta_{L}^{i} w L^{i}-\theta_{M}^{i} p^{M} M^{i}
$$


Each type of wedge increases the cost and reduces the use of a production factor, distorting the input mix. It is key that the distortions are specific to each sector and to each input, generating misallocation in the aggregate. The total distortion can be summarized by the geometric weighted average

$$
\varphi^{i} \equiv\left[\left(\theta_{K}^{i}\right)^{\alpha^{i}}\left(\theta_{L}^{i}\right)^{1-\alpha^{i}}\right]^{\varepsilon^{i}}\left(\theta_{M}^{i}\right)^{1-\varepsilon^{i}}
$$

using factor shares as weights, as shown in Appendix A.2.

\subsubsection{TFP Changes and Efficiency Gains}

In Appendix A.2, we show that we can write aggregate TFP as

$$
T F P=\prod_{i=1}^{n}\left(\omega^{i} \frac{A^{i}}{\Phi^{i}} \psi^{i}\right)^{\frac{\omega^{i}}{\varepsilon}} \varepsilon\left(\frac{1-\varepsilon}{\phi}\right)^{\frac{1-\varepsilon}{\varepsilon}}
$$
with $\psi^{i} \equiv\left[\frac{\varepsilon^{i}}{\varepsilon}\left(\frac{\alpha^{i}}{\alpha}\right)^{\alpha^{i}}\left(\frac{1-\alpha^{i}}{1-\alpha}\right)^{1-\alpha^{i}}\right]^{\varepsilon^{i}}\left(\frac{1-\varepsilon^{i}}{1-\varepsilon}\right)^{1-\varepsilon^{i}}$ and the adjusted relative distortion for each sector $i$ defined
as

$$
\Phi^{i}=\frac{\left[\varepsilon\left(\sum_{j=1}^{n} \omega^{j}\left(\frac{\alpha^{j} \varepsilon^{j}}{\alpha \varepsilon}\right) \frac{\theta_{K}^{i}}{\theta_{K}^{j}}\right)^{\alpha^{i}}\left(\sum_{j=1}^{n} \omega^{j} \frac{\left(1-\alpha^{j}\right) \varepsilon^{j}}{(1-\alpha) \varepsilon} \frac{\theta_{L}^{i}}{\theta_{L}^{j}}\right)^{1-\alpha^{i}}\right]^{\varepsilon^{i}}\left((1-\varepsilon) \sum_{j=1}^{n} \omega^{j}\left(\frac{1-\varepsilon^{j}}{1-\varepsilon}\right) \frac{\theta_{M}^{i}}{\theta_{M}^{j}}\right)^{1-\varepsilon^{i}}}{\left(1-\sum_{j=1}^{n} \omega^{j} \frac{1-\varepsilon^{j}}{\theta_{M}^{j}}\right)^{\varepsilon^{i}}\left(\sum_{j=1}^{n} \omega^{j} \frac{1-\varepsilon^{j}}{\theta_{M}^{j}}\right)^{1-\varepsilon^{i}}}
$$

This term $\Phi^{i}$ represents how distorted sector $i$ is relative to the entire economy. Notice that, from the point of view of each individual sector, an increase in $\Phi^{i}$ is isomorphic to a decline in productivity $A^{i}$.

Equation (4) provides an aggregate measure of allocative efficiency

$$
E \equiv \prod_{i=1}^{n}\left(\Phi^{i}\right)^{-\frac{\omega^{i}}{\varepsilon}}
$$

depending on the distribution of distortions across sectors. In an undistorted economy, $\Phi^{i}=1$ for all sectors, so allocative efficiency is also equal to one. Proportional changes in $\theta_{K}^{j}$ and/or $\theta_{L}^{j}$ across sectors affect the level of absolute distortions but not their dispersion across sectors, leaving relative distortions and allocative efficiency unchanged. However, because we are considering value added TFP, a proportional increase in all $\theta_{M}^{i}$ does increase adjusted relative distortions and reduce aggregate allocative efficiency.

Log-linearizing aggregate TFP around an initial base year 0, we obtain

$$
\widetilde{T F P}=\frac{1}{\varepsilon} \sum_{i=1}^{n} \omega^{i}\left[\widetilde{A^{i}}-\widetilde{\Phi^{i}}\right]
$$

assuming constant weights $\omega^{i}$, factor shares and relative price of intermediates $\phi$. The allocative efficiency gains can be computed as

$$
E_{\text {gain }} \equiv-\frac{1}{\varepsilon} \sum_{i=1}^{n} \omega^{i} \widetilde{\Phi^{i}}
$$

which is a weighted average of the growth of adjusted relative distortions. This number measures how changes in sector specific distortions over time contribute to TFP growth in the distorted economy. Notice that the larger the share of intermediates in production $1-\varepsilon$, the larger the amplifying effect of distortions on efficiency gains. 


\begin{tabular}{|l|cccc|}
\hline & $2003-05$ & $2005-08$ & $2008-09$ & $2009-12$ \\
\hline \hline Mean & 1.07 & 1.06 & 1.05 & 1.06 \\
C.V. (std deviation/mean) & 0.24 & 0.21 & 0.20 & 0.25 \\
90th/10th percentile & 1.39 & 1.46 & 1.46 & 1.54 \\
\hline \hline Correlation with Employment $(L)$ & 0.04 & 0.06 & 0.13 & 0.02 \\
Correlation with Credit/Output & -0.14 & -0.19 & -0.18 & -0.14 \\
Correlation with Interest Rate & 0.01 & 0.09 & 0.06 & 0.08 \\
\hline
\end{tabular}

Table 3: Descriptive Statistics for the Adjusted Relative Distortions $\Phi$

\subsection{Efficiency Gains in the Data}

We measure the sectoral distortions described above from the establishment level data from the EIA. The data is annual and aggregated to the 4-digit NAICS classification. Once we exclude sectors with missing information, we have a total of 82 sectors within manufacturing, each of which is mapped into a sector in the model (so $n=82$ ). The result is a panel of sectoral distortions for 2003-12. Using this information, we compute the efficiency gains to assess the quantitative contribution of distortions to aggregate TFP changes.

\subsubsection{Measuring Sectoral Distortions}

The first order conditions from profit maximization in each sector imply that

$$
\frac{p^{M} M^{i}}{p_{i} Y^{i}}=\frac{1-\varepsilon^{i}}{\theta_{M}^{i}} \quad \frac{w L^{i}}{p_{i} Y^{i}}=\frac{\left(1-\alpha^{i}\right) \varepsilon^{i}}{\theta_{L}^{i}} \quad \frac{r K^{i}}{p_{i} Y^{i}}=\frac{\alpha^{i} \varepsilon^{i}}{\theta_{K}^{i}}
$$

As detailed in Appendix A.1, we have data on gross output, the wage bill, intermediate goods purchased and capital for each sector, all measured at current prices. This allows us to construct the empirical counterparts of the input expenditure shares in the left hand side. ${ }^{11}$ However, since these shares are not independent of distortions, we cannot identify the production function coefficients $\varepsilon^{i}$ and $\alpha^{i}$. Following Hsieh and Klenow (2009), we use factor shares from the corresponding sectors $i$ for the U.S. in 2003 as an example of an undistorted economy. ${ }^{12}$ For each sector $i$ and at each period $t$, wedges are then computed as:

$$
\theta_{M, t}^{i}=\left(1-\varepsilon^{i, u s}\right)\left(\frac{\text { gross output }{ }_{t}^{i}}{\text { intermediates purchases }{ }_{t}^{i}}\right)
$$

and

$$
\theta_{L, t}^{i}=\left(1-\alpha^{i, u s}\right) \varepsilon^{i, u s}\left(\frac{\text { gross output }_{t}^{i}}{\text { wage bill }_{t}^{i}}\right) \quad \theta_{K, t}^{i}=\alpha^{i, u s} \varepsilon^{i, u s}\left(\frac{\text { gross output }_{t}^{i}}{0.092 \times \text { capital stock }_{t}^{i}}\right)
$$

Feeding these measured wedges into equations (3) and (5), we construct panels of total distortions $\varphi_{t}^{i}$ and adjusted relative distortions $\Phi_{t}^{i}$ for each sector and year. Table 3 reports some descriptive statistics for

\footnotetext{
${ }^{11}$ To get the rental rate of capital we use a 9.2 percent rate of return, obtained as the sum of an average real interest rate on loans of 2.2 percent and an average depreciation rate of 7 percent, both obtained from our dataset.

${ }^{12}$ We compute the sectoral factor shares for the U.S. economy using industry level data from the BEA. The intermediate share corresponds to all expenditures in intermediate goods divided by gross output. We measure the labor share as total wages, salaries and complements divided by gross output. Assuming constant returns to scale, we obtain the capital share as a residual. To get an idea of the magnitudes, the resulting weighted averages for these shares are $\varepsilon=0.69$ and $\alpha=0.45$.
} 


\begin{tabular}{|l|cccc|}
\hline \multicolumn{1}{|c|}{ Average yearly \% changes } & 2003-05 & $2005-08$ & $2008-09$ & $2009-12$ \\
\hline \hline Observed TFP growth & 1.91 & 1.22 & -7.32 & 1.08 \\
\hline \hline Measured efficiency gains & -0.13 & 0.68 & 0.45 & 0.81 \\
Correlation $\left(\widetilde{\varphi}_{t}^{i}, \omega^{i}\right)$ & 0.01 & -0.06 & -0.02 & -0.12 \\
Correlation $\left(\widetilde{\varphi}_{t}^{i}, \omega^{i} \varphi_{0}^{i}\right)$ & 0.00 & -0.13 & -0.10 & -0.09 \\
\hline
\end{tabular}

Table 4: TFP Growth and Efficiency Gains

$\Phi$ (results for $\varphi$ are very similar). The average distortion is almost unchanged throughout the period, but its dispersion falls until 2009. Adjusted relative distortions are positively correlated with employment, i.e., larger sectors tend to be more distorted. This correlation with employment increased sharply in the 2008-09 crisis and fell again in the recovery period thereafter.

Table 3 also shows the relationship between distortions and credit conditions, which is key to our story. Adjusted relative distortions are negatively related to the credit to output ratio across sectors, and positively related to interest rates. Sectors with lower availability and higher cost of credit tend to be more distorted. Although these simple statistics do not imply causality, they nevertheless provide a motivation to study the role of credit conditions as a source of misallocation and deviations from the optimal inputs mix.

\subsubsection{TFP Growth and Efficiency Gains}

We finally use equation (8) to compute the allocative efficiency gains obtained in the data from the changes in distortions over time. Table 4 shows aggregate TFP growth in the data and our measure of efficiency gains. These gains accounted for about half the pre-crisis TFP growth and about 80 percent of the recovery. Our analysis suggests that efficiency actually deteriorated in the early years of the sample. We also find that efficiency gains mitigated the large loss of TFP in the recession. ${ }^{13}$ To summarize in one number the contribution of efficiency to TFP movements in the whole period, we compute the variability (as the standard deviation of the log) of aggregate TFP over time and obtain 3.13 percent. A similar statistic for allocative efficiency, as defined in equation (6), gives us 2.35 percent. ${ }^{14}$ Hence efficiency gains account for 75 percent of TFP variability over time.

The last two rows in Table 4 help us to understand these movements in efficiency. For this, notice that a decline in adjusted relative distortions $\Phi^{i}$ for a sector contributes positively to TFP growth, and the size of this contribution is weighted by the share of this sector in gross output $\omega^{i}$. Such a decline occurs whenever total distortions $\varphi^{i}$ move closer to the average across sectors. In other words, a positive contribution to TFP growth occurs whenever a highly distorted sector reduces its distortions. Consistently with this analysis, Table 4 reports a negative correlation between the growth rate in total distortions and the sectoral weights for all periods with a positive efficiency gain. Moroever, in these periods we also observe a negative correlation

\footnotetext{
${ }^{13}$ From equation (7), this implies that the bulk of the contraction in aggregate TFP during the 2009 recession needs to be accounted for by a fall in the sectoral Solow residuals $\left(A^{i}\right)$. A possible explanation is the closing of export markets with the trade disruption that accompanied the global financial crisis which functioned as a demand shock. Notice also that changes in firm level distortions within each sector could also show up in these sectoral residuals. These are all interesting topics beyond the scope of our paper.

${ }^{14}$ These two numbers are reported later in the last column of Table 5.
} 
between the growth rate in total distortions and their (weighted) initial value. The 2003-2005 period of efficiency losses shows little correlation between the initial distortion and its change.

Summing up, our simple accounting exercise finds an important role for sectoral distortions in aggregate TFP movements in Mexican manufacturing. The key message of our decomposition exercise is that changes in the distribution of distortions across sectors matter for aggregate TFP growth. An increase in distortions in a large and already distorted sector penalizes TFP growth heavily, whereas a reduction in the distortion of a small and relatively undistorted sector is not necessarily beneficial. This is a dynamic version of the static result that the dispersion of distortions matters for the degree of misallocation and the aggregate TFP level (see Restuccia and Rogerson, 2008).

So far we have taken distortions as primitives. In the remaining sections of the paper we endogenize them in the context of a model with financial frictions and explore the role of credit conditions in shaping the evolution of these wedges and, therefore, in explaining changes in aggregate TFP.

\section{Financial Frictions and Sectoral Distortions}

We now present a simple static model of a firm's choice of inputs under two types of financial frictions: a working capital constraint on the purchase of variable inputs (labor and intermediate goods), and a borrowing constraint. These two frictions introduce wedges between factor prices and marginal products which can be mapped into the sector specific distortions defined in the previous section, creating a link between credit conditions (price and availability of credit), distortions, and aggregate TFP. We calibrate this model and feed in the observed panels of credit conditions to compute the implied efficiency gains, which we then compare to the observed TFP growth and efficiency gains reported in Section 3.

\subsection{Introducing Financial Frictions}

As before, the representative firm in sector $i$ purchases capital and labor services and intermediate goods to produce output, according to the production function specified in (1). We introduce two types of financial frictions. First, the firm has to finance its working capital (including labor services and intermediates purchases) either through loans from banks or loans from suppliers (trade credit), both repaid at the end of the period. Loans from banks carry a sector specific interest rate $\iota_{t}^{i}$ that we take as exogenous. Loans from suppliers are more expensive and include an exogenous interest rate premium $\rho$. The second friction is that loans from banks are constrained to be no larger than a fraction $\xi_{t}^{i}$ of the value of the firm's sales.

A large literature on trade credit informs our modelling choices. Two empirical facts about this form of financing are well established. First, trade credit is used more intensively by firms which are credit constrained. ${ }^{15}$ Cotler (2013) documents the importance of trade credit for Mexico using the ENAFIN survey carried out by the Central Bank of Mexico. He finds that 82 percent of all businesses report using trade

\footnotetext{
${ }^{15}$ See for example, the evidence for U.S. firms in Petersen and Rajan (1994 and 1997). Gama et al. (2010) find this to be true for a panel of Portuguese and Spanish firms, while Couppey-Soubeyran and Hericourt (2013) find that firms in the MENA region that have difficulty gaining access to bank credit use trade credit instead. Atanasova and Wilson (2003) find that the use of trade credit increases during periods of monetary contractions in the U.K. Also, the use of trade credit is more prevalent in countries with poor enforcement and less developed financial systems. Demirguc-Kunt and Maksimovic (2001) find that the magnitude of bank credit relative to trade credit is higher in countries with more efficient legal systems, while Fisman and Love (2003) find that industries with higher dependence on trade credit grow faster in countries with weaker financial institutions.
} 
credit to finance their expenses, and most of them simultaneously use bank credit. The sample includes firms of various sizes operating in different sectors of the economy, including manufacturing. Second, trade credit tends to be substantially more expensive than bank credit. ${ }^{16}$ Our calculations from ENAFIN reveals that the cost of this credit was about 5 percent per month, or $80 \%$ annualized.

\subsubsection{The Firm's Problem with Financial Frictions}

The problem of the representative firm in each sector $i$ is to solve

$$
\begin{array}{rc}
\max _{\left\{L^{i}, K^{i}, M^{i}, \kappa^{i}\right\}} & \left.p^{i} Y^{i}-r K^{i}-\left[1+\iota^{i}+\left(1-\kappa^{i}\right) \rho\right)\right]\left(w L^{i}+p^{M} M^{i}\right) \\
\text { s. to } \quad & Y^{i}=A^{i}\left[\left(K^{i}\right)^{\alpha^{i}}\left(L^{i}\right)^{1-\alpha^{i}}\right]^{\varepsilon^{i}}\left(M^{i}\right)^{1-\varepsilon^{i}} \\
& \kappa^{i}\left(w L^{i}+p^{M} M^{i}\right) \leq \frac{\xi^{i} p^{i} Y^{i}}{1+\iota^{i}}, \quad 0 \leq \kappa^{i} \leq 1,
\end{array}
$$

where $\kappa^{i}$ is the endogenous fraction of working capital financed through banks (which we refer to as simply credit from now onwards). Together with the interest rate $\iota^{i}$, the parameter $\xi^{i}$ captures credit conditions by governing the tightness of the borrowing constraint. These credit conditions affect sectors differently, as shown before in the data. The firm takes factor prices $\left(w, r, p^{M}\right)$ and sectoral output prices $\left(p^{i}\right)$ as given.

\subsubsection{Mapping Credit Conditions into Sectoral Distortions}

In Appendix A.3 we characterize the solution to the firm's optimization problem (9). We show that the first order conditions of this problem imply the following mapping between credit conditions and the total distortion for each sector defined in equation (3):

$$
\varphi^{i}=\frac{1+\iota^{i}}{1+\iota^{i}+\lambda^{i} \xi^{i}}\left[1+\iota^{i}+\left(1-\kappa^{i}\right) \rho+\kappa^{i} \lambda^{i}\right]^{1-\alpha^{i} \varepsilon^{i}}
$$

where $\lambda^{i}$ is the Lagrange multiplier associated to the borrowing constraint. Notice that distortions are now endogenous and depend on the sector-specific credit conditions $\left(\iota^{i}, \xi^{i}\right)$ together with two endogenous variables $\left(\lambda^{i}\right.$ and $\left.\kappa^{i}\right)$. They arise because the shadow cost of credit increases the effective cost of labor and of intermediates relative to output, distorting the optimal mix of inputs.

In Appendix A.3 we further characterize the solution to the firm's optimization problem and show how, depending on the tightness of the borrowing constraint relative to other parameters, the firm will be in one of three regimes:

1. For high tightness the borrowing constraint binds but $\kappa^{i}<1$. Available bank credit is not sufficient to purchase all inputs and the firm has to tap into the more expensive trade credit. Then,

$$
\varphi^{i}=\frac{1+\iota^{i}}{1+\iota^{i}+\rho \xi^{i}}\left[1+\iota^{i}+\rho\right]^{1-\alpha^{i} \varepsilon^{i}}
$$

\footnotetext{
${ }^{16}$ A study of more than 30,000 trade credit transactions by Klapper et al. (2012) in the U.S. and Europe shows that the median annual interest rate on these transactions is $54 \%$.
} 
2. For intermediate tightness the borrowing constraint binds and $\kappa^{i}=1$. Available bank credit allows firms to avoid trade credit, but their purchase of inputs is still constrained. In this case,

$$
\varphi^{i}=\left(1+\iota^{i}\right)^{1-\alpha^{i} \varepsilon^{i}}\left(\frac{\alpha^{i} \varepsilon^{i}}{1-\xi^{i}}\right)^{\alpha^{i} \varepsilon^{i}}\left(\frac{1-\alpha^{i} \varepsilon^{i}}{\xi^{i}}\right)^{1-\alpha^{i} \varepsilon^{i}} .
$$

3. For low tightness the borrowing constraint is not binding and $\kappa^{i}=1$. Firms' purchase of inputs is unconstrained and all of it is financed through bank credit. Therefore,

$$
\varphi^{i}=\left(1+\iota^{i}\right)^{1-\alpha^{i} \varepsilon^{i}} .
$$

As the above equations make clear, an increase in the sector specific interest rate always increases total distortions. A relaxation of the borrowing constraint, i.e. an increase in the availability of credit reduces distortions in the first case and second case, ${ }^{17}$ until the point in which the firm becomes unconstrained in the third case. Since inputs have to be purchased in advance of production, interest rates always introduce a wedge between the optimal and the actual input ratios.

\subsection{Accounting for Observed Efficiency Gains}

Our quantitative experiment consists of feeding the model with the entire panel of data of borrowing limits and interest rates taken from the data as exogenous variables and solve it as a sequence of static problems. From the previous subsection and Appendix A.3, we know that credit conditions together with factor shares and the interest rate premium for credit from suppliers determine distortions and therefore efficiency gains. In our setup, this relation is independent from the sectoral productivity parameters $A_{t}^{i}$ and from factor prices, which allows us to avoid the issues of how to compute sectoral Solow residuals without sectoral price deflators. $^{18}$

\subsubsection{Calibration}

From the analysis in Section 3, we already have factor shares $\alpha^{i}, \varepsilon^{i}$ for each of the 82 sectors (taken as their U.S. counterparts) and calibrate the weights $\omega^{i}$ as the proportion of each sector's gross output in the total value of manufacturing output in 2003. An additional parameter in the model is the interest rate premium $\rho$ for loans from suppliers, which we do not have in our data. In our calibration, we use a conservative value of $\rho$ of 15 percent and test for robustness using a range of other values in Section $5 .{ }^{19}$ We keep factor shares, sectoral weights and the trade credit premium constant over time.

The panel for interest rates $\iota_{t}^{i}$, is the sector specific real interest rate which will represent one of our exogenous parameters affecting credit conditions. We measure real interest rates as the interest rate on

\footnotetext{
${ }^{17}$ Note that in the intermediate tightness regime $\frac{\partial \varphi^{i}}{\partial \xi^{i}} \leq 0$ if $\xi^{i} \leq\left(1-\alpha^{i} \varepsilon^{i}\right)$ which is always true in this regime. More details of the solution can be found in Appendix A.3

${ }^{18}$ In the working paper version of the paper we embedded the firm's problem in a dynamic general equilibrium model of the economy. Not surprisingly, the results for efficiency gains are the same. The general equilibrium model allows us to obtain testable predictions on other variables, though, such as the distribution of inputs and output across sectors. In particular, the general equilibrium model delivers an allocation of labor across sectors and over time that closely matches the data. These results are available upon request.

${ }^{19}$ Estimates of the cost of trade credit in Mexico from the ENAFIN suggest a median annual rate of almost 80 percent, mostly in the form of early payment discounts. Petersen and Rajan (1994) document that a substantial fraction of firms do not take advantage of these discounts.
} 
the average loan in the sector in the current year, deflated by the change in the manufacturing price level. The other parameter related to credit is the tightness $\xi_{t}^{i}$ of the borrowing limit. To identify this parameter we need to assume that the borrowing constraint is binding for each sector and in each year. ${ }^{20}$ Then we construct

$$
\xi_{t}^{i}=\left(1+\iota_{t}^{i}\right)\left(\frac{\text { short term credit }_{t}^{i}}{\text { gross output }_{t}^{i}}\right)
$$

combining the short term credit flow information from R04C and the real data from EIA. This identification strategy implies that in our model, as well as in the evidence reported by Cotler (2013), most firms use simultaneously bank loans and trade credit.

\subsubsection{Distortions and Efficiency Gains}

The mapping between credit conditions and distortions derived in Appendix A.3 allows us to construct adjusted relative distortions $\Phi^{i}$, and efficiency gains in the model, using equations (5) to (8). These are exclusively functions of credit conditions, factor shares and the interest rate premium for trade credit.

Table 5 reports our results on efficiency gains in the baseline model, comparing them with those in the data. The model is able to account for a substantial amount of the improvements in allocative efficiency. The biggest success is in the recovery period of 2009-12 where the model explains almost 80 percent of the efficiency gains, and 60 percent of the observed TFP growth. The model efficiency gains in the 2005-08 period are also substantial, in that they account for almost all the gains in TFP in that period, although they overpredict efficiency gains in the data. In the first period, 2003-05, the model accounts for 60 percent of the efficiency losses, even though there is positive TFP growth in the data. Our model does not do well in predicting the recession. As the data shows, the fall in TFP during the recession can be attributed to a fall in the sectoral Solow residuals. Since financial conditions worsened for almost all sectors, and our model attributes all efficiency changes to variations in interest rates and credit constraints, we predict an efficiency loss.

The last column of Table 5 compares the variability in aggregate TFP over time during the whole period with the variabilities in aggregate efficiency in the data and in the model. We calculate the standard deviation of the logarithm of the annual 2003-2012 levels of TFP and allocative efficiency, as defined in equation (6). As discussed in the previous section, allocative efficiency in the data accounts for 75 percent of the variability in TFP. Importantly, our baseline model predicts 56 percent of the variability in allocative efficiency in the data. This provides further evidence that changes in the cost and availability of credit have an important role to play in the allocation of resources.

Table 6 looks at a more disaggregated fit of the data, and compares predicted moments for the whole panel of adjusted relative distortions with their data counterparts, constructed as described in Section 3 . The model matches the mean and autocorrelation of $\Phi_{t}^{i}$ quite well. ${ }^{21}$ The distortions in the model arise entirely from financial frictions, while in the data they could exist for a variety of reasons. The model therefore predicts a relatively small dispersion, as compared to the data. The model also predicts that higher interest

\footnotetext{
${ }^{20}$ As we mentioned previously, the borrowing constraint is binding in two out of three cases. Appendix A.3 shows that being in a regime of binding constraints depends on the value of $\xi_{t}^{i}$ being strictly smaller than $1-\alpha^{i} \varepsilon^{i}$. We check whether this is true or not in the data. If it is not, we set $\xi_{t}^{i}=1-\alpha^{i} \varepsilon^{i}$. In this way we eliminate the third case and assume that the borrowing constraint is always binding or tangent. In the data we find that the third case, the borrowing constraint not binding, occurs only for a small fraction (less than 10 percent) of sector-years.

${ }^{21}$ Results for $\varphi^{i}$ are very similar.
} 


\begin{tabular}{|l|cccc||c|}
\hline \multicolumn{1}{|c|}{ Average yearly \% changes } & $2003-05$ & $2005-08$ & $2008-09$ & $2009-12$ & $\begin{array}{c}\text { Variability, \% } \\
2003-12\end{array}$ \\
\hline \hline \multirow{2}{*}{ TFP Growth } & & & & & TFP \\
Data & 1.91 & 1.22 & -7.32 & 1.08 & 3.13 \\
\hline \hline \multirow{2}{*}{ Efficiency Gains } & & & & & Efficiency \\
Data & -0.13 & 0.68 & 0.45 & 0.81 & 2.35 \\
Baseline experiment & -0.08 & 1.07 & -2.21 & 0.63 & 1.31 \\
\hline
\end{tabular}

Table 5: TFP Growth and Efficiency Gains in the Baseline Experiment

\begin{tabular}{|l|cc|cc|}
\hline \multicolumn{1}{|c|}{ Statistics for $\Phi_{t}^{i}$} & \multicolumn{2}{c|}{ Data } & \multicolumn{2}{c|}{ Model } \\
\hline \hline Mean & \multicolumn{2}{|c|}{1.06} & 0.99 \\
SD/Mean & \multicolumn{2}{|c|}{0.24} & 0.05 \\
Autocorrelation & \multicolumn{2}{|c|}{0.95} & 0.91 \\
\hline \hline Regression: & & & \\
Dependent Variable $\Phi_{i t}$ & Coeff & Std.Err & Coeff & Std. Err \\
\hline Interest Rate & 0.10 & 0.03 & 0.49 & 0.05 \\
Credit/Output & -0.14 & 0.03 & -0.12 & 0.01 \\
Constant & 1.09 & 0.01 & 1.00 & 0.00 \\
\hline
\end{tabular}

Table 6: Data and Model Predicted Moments for Distortions

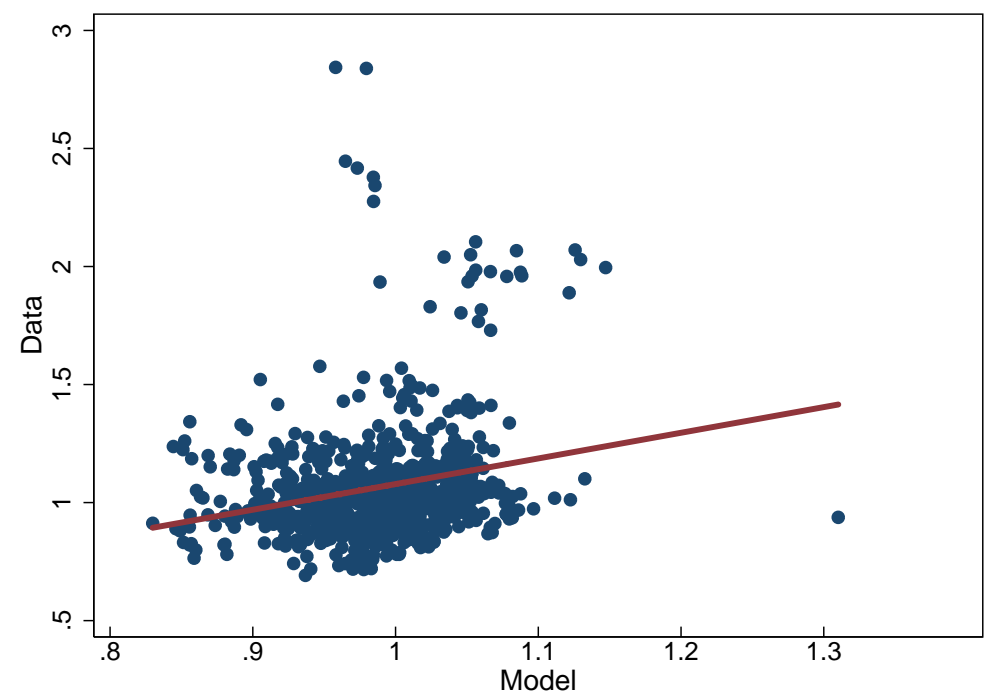

Figure 3: The Adjusted Relative Distortion, $\Phi_{i t}$ in the Data and in the Model 
rates and tighter access to credit give rise to larger distortions, as in the data. A regression of $\Phi_{t}^{i}$ against the cost and availability of credit produces similar coefficients in the model and in the data. Finally, Figure 3 plots the model predicted $\Phi_{i t}$ against its data counterpart for the entire panel. The linear predictor through these variables has a slope close to that of the 45 degree line (1.08) and their correlation is 0.24.

Taken together, the results suggest that our model is able to generate wedges between prices of inputs and marginal products that resemble the type of sectoral distortions observed in the data. In particular, the mapping between credit conditions and distortions implied by the model is also supported in the data, strenghtening the story of financial frictions as an important source of misallocation.

\subsubsection{The Role of Aggregate Credit Conditions}

To better understand our results, it is useful to look back at Figure 2 which plots the cross sectional average of the real interest rates and the credit to output ratios. Recall that the tightness of the borrowing constraint is a function of the credit intensity and the interest rate. The period up to 2006 saw a relatively tight borrowing constraint on average, a result of both low credit to output ratios and high interest rates. The constraint loosened from 2006 to 2008, reflecting the credit expansion. Notice that credit conditions worsened in 2009, as the flow of credit fell along with an increase in interest rates. In the recovery period, the constraint actually tightened on average, reflecting the stagnation of aggregate credit in the data.

We would therefore expect both financial shocks to have negative effects on allocative efficiency in 2003-05, and the reverse in 2005-08. During the 2009 recession, while the borrowing constraint is almost constant, we would expect the increase in interest rates to increase distortions and reduce TFP. Finally, there are two contradictory forces in the recovery period: the low interest rates are expansionary but the stagnation in credit works in the reverse direction. The net effect of these forces was of course a quantitative question.

Obviously these averages do not capture the complete story since they ignore sectoral heterogeneity, which plays an important role in our model and in the data. A tightening of the borrowing constraint on average is consistent with an increase in aggregate TFP if the more distorted sectors increase their borrowing. Similarly high average interest rates may hide low interest rates for some specific sectors. One of the goals of our quantitative experiments in the next Section 5 is to assess the impact of this heterogeneity.

\subsection{Financial Frictions and TFP Levels}

Before moving to the counterfactuals, it is worth analyzing the implications of financial frictions for the level of TFP. Although our goal is to study how changes in credit conditions affect TFP growth, most of the literature on misallocation has focused on differences in TFP levels. For instance, as discussed in the introduction, Gilchrist et al. (2013) and Midrigan and Xu (2014) find that financial frictions have a small impact on the level of TFP (between 3.5 in the former to 5-10 percent in the latter). A natural question is whether our exercise is consistent with these results.

From equation (4), we can write the static TFP losses due to misalocation as $1-\prod_{i=1}^{n}\left(\Phi^{i}\right)^{-\frac{\omega^{i}}{\varepsilon}}$. This number reflects how much smaller the level of TFP is in our model compared to the ideal undistorted TFP level in the efficient allocation. We feed this formula with the adjusted relative distortions $\Phi^{i}$ calibrated in our baseline model with financial frictions for the initial year 2003 and obtain a static misallocation loss of 
8.5 percent. This number lies in the upper range of Midrigan and $\mathrm{Xu}$ (2014), and is more than double the estimate of Gilchrist et al. (2013).

The exercise in Gilchrist et al. (2013) is the closest to ours. As a first step, they retrieve firm specific interest rates from the data and take the cross sectional dispersion in borrowing costs as exogenous. ${ }^{22}$ Then, they feed a simple static model with working capital constraints with these interest rates and compute the TFP losses in levels. One important difference between our setup and theirs is that we incorporate financial frictions to the purchase of intermediate goods, which have a large share in gross output. Our dispersion in borrowing costs is also larger than theirs. Gilchrist et al. (2013) report an average real interest rate of 2.4 percent with a standard deviation of 1.7 across firms (see their Table 2). In our sample, the mean interest rate is about the same (2.2), but the standard deviation across sectors is 2.8 , as shown in Table 1. Finally, these authors abstract from credit constraints, which, as we will see in the next section, play an amplifying role in our model.

Midrigan and Xu (2014) build a general equilibrium model of firm dynamics à la Hopenhayn with working capital constraints and a common, time invariant, credit constraint. The model is calibrated to match some facts about the size and productivity distributions of firms in Korea and Colombia, and the TFP losses are computed from the stationary distribution of the model. In their setup, financial frictions create the same type of allocative inefficiencies as in our model, but only for small firms. The ability of firms to accumulate capital over time allows them to undo the effects of borrowing limits, so the overall impact of financial frictions is reduced. We do not have this dynamic mechanism in our setup; our focus is at the sectoral level, in which the assumption of constant returns to scale precludes any firm dynamics. Notice, though, that our borrowing limit $\xi_{t}^{i}$ for each sector is time varying. Unlike Midrigan and Xu (2014), we have disaggregated information on credit flows and interest rates. Given calibrated parameter values and information on real and financial variables, our model can predict whether a particular sector is constrained or not in each period. As mentioned in the calibration section, the data shows that more than 90 percent of all sector-year observations are constrained.

\section{Sources of Efficiency Gains}

Finally, we perform some counterfactual experiments to further explore the sources of the efficiency gains implied by the model. We consider alternative experiments where we vary only the borrowing limit or the interest rates, or eliminate the heterogeneity in credit conditions across sectors. We also explore the results of a model with financial frictions to labor only, and perform some sensitivity analysis with respect to alternative values of the trade credit premium. The results are summarized in Table 7.

\subsection{Interest Rates vs. Borrowing Limits}

What are the contributions of each financial shock to efficiency gains? To answer this question, we perform two counterfactual experiments, the results of which are reported in panel (a) of Table 7 . The first experiment shuts down interest rate variations and freezes all sectors at their 2003 interest rate. This allows us to

\footnotetext{
${ }^{22}$ The source for this data, Compustat, tracks bond issuances for a subset of U.S. large manufacturing corporations. The authors use information from 1985 to 2010, although their statistics of dispersion are averaged over time.
} 


\begin{tabular}{|l|cccc|}
\hline \multicolumn{1}{|c|}{ Efficiency Gains (\%) } & 2003-05 & 2005-08 & 2008-09 & 2009-12 \\
\hline \hline Baseline experiment & -0.08 & 1.07 & -2.21 & 0.63 \\
\hline (a) Model with changes only in: & & & & \\
(a1) Borrowing limit $\xi_{t}^{i}$ & -0.10 & 0.09 & 0.00 & -0.15 \\
(a2) Interest rate $\iota_{t}^{i}$ & 0.03 & 0.99 & -2.22 & 0.77 \\
(b) Eliminating borrowing constraint & 0.22 & 0.25 & -0.49 & 0.14 \\
\hline (c) Eliminating heterogeneity in financial shocks & -1.59 & 1.29 & -1.62 & 0.22 \\
\hline (d) Model with financial frictions only on labor & 0.05 & 0.00 & 0.02 & 0.00 \\
\hline (e) Model with alternative trade credit premia & & & & \\
(e1) Lower premium: $\rho=0.05$ & 0.11 & 0.60 & -1.27 & 0.41 \\
(e2) Higher premium: $\rho=0.25$ & -0.26 & 1.37 & -2.73 & 0.64 \\
\hline
\end{tabular}

Table 7: Sources of Efficiency Gains

quantify the role of movements in the borrowing limits. The second experiment, analogously, assesses the role of interest rate movements through the period, keeping borrowing limits constant at their 2003 levels.

The results show that the variations in borrowing limits played a relatively minor role in explaining the movements in efficiency. An exception is the initial period of 2003-05, where tight credit exacerbated the misallocation of resources. As Table 2 shows, the credit to output ratio fell by more than 20 percent for sectors where it fell, whereas sectors which expanded, did so only at 8 percent. In other periods, however, the role of borrowing limits seems to be modest. The second experiment further illustrates the salience of interest rate movements. Apart from the initial period, variations in interest rates account for almost all of the model predicted efficiency gains. This is particularly interesting in the recovery period of 2009-12, where, despite unfavourable credit conditions, the lower cost of credit allowed previously distorted sectors to move closer to their optimal input mix.

This is not to say that the borrowing limits themselves are unimportant. Row (b) of the table shows the effect of eliminating the borrowing constraint completely while maintaining the working capital constraint. This also eliminates the choice between bank and trade credit, since the optimal solution is to always use the cheaper bank credit. The results show that the borrowing constraint does have an important effect on efficiency. In periods where the constraint was tight (2003-05 and the 2009 recession), the elimination of the constraint produces large efficiency gains. Even in other periods, the elimination of the constraint has important, and not necessarily positive effects. In the baseline model, a fall in the interest rate has two consequences: it lowers the effective cost of inputs, and relaxes the borrowing constraint. The existence of a borrowing constraint therefore amplifies the effects of interest rates.

\subsection{The Role of Heterogeneity}

As our accounting exercise in Section 3 emphasizes, changes in the distribution of distortions matter for aggregate efficiency gains. An increase in distortions in a large, already distorted sector can drag efficiency down by much more than a similar increase in a small, less distorted sector. The data also reveals substantial heterogeneity in credit growth and interest rate changes across sectors. It is therefore interesting to assess 
the extent to which this heterogeneity in credit conditions can account for aggregate efficiency.

Panel (c) of Table 7 reports the results of an experiment where we completely eliminate the crosssection heterogeneity in credit conditions. The exercise is the following: we calculate the yearly cross-section mean of the borrowing constraint parameters $\xi_{t}^{i}$ and of interest rates $\iota_{t}^{i}$, and subject every sector to this same yearly shock. ${ }^{23}$ We find that heterogeneity matters in all periods. Efficiency losses in 2003-05 would have been far larger if all sectors faced the same financial shocks. Similarly, a large part of the recovery (approximately 65 percent) is driven by the fact that despite a generalized credit crunch, credit flows were channelled to highly distorted sectors. This is in contrast with the 2005-08 period, where a broad expansion in credit and lowering of interest rates was not targeted to the most distorted sectors. ${ }^{24}$

\subsection{Distortions on the Use of Individual Inputs}

We now modify the model and assume financial frictions exist only on the purchase of labor, not on intermediate goods. The borrowing constraint remains as in the baseline, but applies only to the wage bill. We find huge differences between the results of this experiment, reported in row (d), and the baseline. Without distorting intermediate goods, which represent on average about 65 percent of factor payments in gross output, almost all of the efficency gains generated by the model disappear. This implies that financial frictions in the purchase of intermediate goods are the most important source of aggregate TFP changes in our analysis.

\subsection{Alternative Values of Trade Credit Premium}

Finally, we consider alternative values of the trade credit premium. We assume in the model that trade credit is more expensive than bank credit by a constant interest rate premium $\rho$ and use a value of 15 percent for it in the calibration of the baseline model. Given that we do not have direct data on the cost of trade credit, we try two alternative values: a low premium of 5 percent and then a large premium of 25 percent. We report the results in Panel (e) of Table 7. Although none of the results change qualitatively with respect to the baseline, there are some quantitative changes. A low premium mitigates the impact of credit conditions on TFP growth in periods where interest rates fall, while a high premium amplifies it. However, it is important to highlight that for these two alternative premia the model still accounts for large fractions of the observed efficiency gains.

\section{Conclusions}

In this paper we examine the role of credit conditions on the allocation of inputs and the consequences for aggregate TFP. Unlike several other studies, we focus on changes in TFP and their relation to the variation in the cost and availability of credit, rather than on productivity levels.

We develop a new dataset that combines information on real variables such as output, investment and variable inputs, with financial information on credit flows and interest rates disaggregated at a 4-digit

\footnotetext{
${ }^{23}$ In this experiment we keep heterogenous income shares across sectors. We have another experiment in which we assume an identical share for all sectors, calculated as a weighted average share across sectors. Results are almost identical to the ones shown in Table 7.

${ }^{24}$ Gopinath et al. (2015) find a similar phenomenon in Southern Europe where a credit boom and lower interest rates attributed to the euro-convergence process led to a decline in efficiency.
} 
industrial sector level. Using this information, we first establish an accounting framework that links aggregate TFP gains with changes in allocative efficiency. Computing both these objects from the data, we find that efficiency gains are a large part of TFP growth. Our framework also indicates that efficiency gains in all sectors are not equal: large, heavily distorted sectors which improve their efficiency contribute more to TFP growth than smaller or relatively undistorted sectors.

We then construct a model that maps efficiency gains into changes in the cost and availability of credit, which we calibrate from the data. The model accounts for 56 percent of the variability in efficiency gains in the data. We find that heterogeneity in credit conditions across sectors is an important element of our analysis. Despite stagnation in aggregate credit, lower interest rates and the allocation of credit to heavily distorted sectors increases efficiency in the recovery from the 2009 recession and can explain more than half of the improvement in efficiency in that period. This suggests a mechanism by which credit-less recoveries, as documented by Calvo et al. (2006) occurs and points to the importance of disaggregated analysis.

A caveat to our results is that the analysis is at the sectoral, not at the firm level. Our unit of analysis is a narrowly defined (4-digit) sector within manufacturing activity, modelled as a representative firm operating a constant returns to scale technology. In contrast with most of the literature on misallocation, we abstract from differences in distortions among firms within the same sector. This is arguably a limitation of our analysis, which is driven by the data availability. However, it also helps us to focus on the sectoral margin and isolate the impact of distortions on the optimal input mix from issues related with the optimal size of firms. Our results show the quantitative importance of this margin is indeed significant.

\section{References}

[1] Atanasova, C.V., \& Wilson, N. (2003). "Bank Borrowing Constraints and the Demand For Trade Credit: Evidence from Panel Data". Managerial and Decision Economics, 24, pp. 503-514.

[2] Bartelsman, E., Haltiwanger, J., \& Scarpetta, S. (2013). "Cross-country differences in productivity: the role of allocation and selection." American Economic Review, 103(1), pp. 305-334.

[3] Benjamin, D., \& Meza, F. (2009). "Total Factor Productivity and Labor Reallocation: The Case of the Korean 1997 Crisis". The B.E. Journal of Macroeconomics, 9(1), pp. 1-41.

[4] Bollard, A., Klenow, P.J. \& Sharma, G. (2013). "India's Mysterious Manufacturing Miracle". Review of Economic Dynamics, 16, pp. 59-85.

[5] Buera, F. \& Moll, B. (2015). "Aggregate Implications of a Credit Crunch". American Economic Journal: Macroeconomics, 7(3), pp. 1-42.

[6] Calvo, G., Izquierdo, A. \& Talvi, E. (2006). "Sudden Stops and Phoenix Miracles in Emerging Markets" American Economic Review, 96(2), pp. 405-410.

[7] Carabarin, M., de la Garza, A., \& Moreno, O. (2015). "Global Liquidity and Corporate Financing in Mexico". Banco de Mexico Working Paper.

[8] Chari, V. V., Kehoe, P., \& McGrattan, E. (2007). "Business Cycle Accounting". Econometrica, 75(3), pp. 781-836. 
[9] Chen, K., \& A. Irarrazabal (2015). "The Role of Allocative Efficiency in a Decade of Recovery". Review of Economic Dynamics, forthcoming.

[10] Cotler, P. (2013). "Does Trade Credit say anything about Bank Credit?". Mimeo.

[11] Couppey-Soubeyran, J. \& Hericourt, J. (2013). "The relationship between trade credit, bank credit and financial structure: from firm-level non-linearities to financial development heterogeneity. A study on MENA firm level data". Review of Middle East Economics and Finance, 9(2), pp. 197-239.

[12] Davis, S. \& Haltiwanger, J. (1992). "Gross job creation, gross job destruction, and employment reallocation". Quarterly Journal of Economics 107, pp. 819-863.

[13] Dekle, R. \& Vandenbroucke, G. (2010). "Whither Chinese Growth: A Sectoral Growth Accounting Approach". Review of Development Economics, 14(3), pp. 487-498.

[14] Demirguc-Kunt, A. \& Maksimovic, V. (2001). "Firms as Financial Intermediaries: Evidence from Trade Credit Data". World Bank Policy Research Working Paper No. 2696.

[15] Estevao, M. \& Severo, T. (2014). "Shocks, financial dependence and efficiency: Evidence from U.S. and Canadian industries". Canadian Journal of Economics, 47(2) pp. 442-465.

[16] Fisman, R. \& Love, I. (2003). "Trade Credit, Financial Intermediary Development and Industry Growth". Journal of Finance, 57(1), pp. 353-374.

[17] Gama, A.P., Mateus, C. \& Teixiera, A. (2010). "Does Trade Credit facilitate access to Bank Finance? Empirical Evidence from Portugese and Spanish small and medium sized enterprises". International Research Journal of Finance and Economics, 45, pp. 26-45.

[18] Gertler, M. \& Gilchrist S. (1994). "Monetary Policy, Business Cycles, and the Behavior of Small Manufacturing Firms". Quarterly Journal of Economics, 109(2), pp. 309-340.

[19] Gilchrist, S., Sim, J. \& Zakrajsek, E. (2013). "Misallocation and Financial Market Frictions: Some Direct Evidence from the Dispersion in Borrowing Costs," Review of Economic Dynamics, 16(1), pp 159-176.

[20] Gopinath, G., Kalemli-Ozcan, S., Karabarbounis, L., \& Villegas-Sanchez, C. (2015) "Capital Allocation and Productivity in South Europe". Mimeo.

[21] Herrera, A. , Kolar, M. \& Minniti, R. (2011). "Credit Reallocation". Journal of Monetary Economics, 58, (6-8), pp. 551-563,

[22] Hsieh, C.-T., \& Klenow, P. (2009). "Misallocation and Manufacturing TFP in China and India". Quarterly Journal of Economics, 124(4), pp. 1403-1448.

[23] Klapper, L., Laeven, L. \& Rajan, R.G. (2012). "Trade Credit Contracts", Review of Financial Studies, 25(3), pp. 838-867.

[24] Klenow, P.J. \& Rodriguez-Clare, A. (1997). "The Neoclassical Revival in Growth Economics: Has It Gone Too Far?" In NBER Macroeconomics Annual 1997, edited by Ben S. Bernanke and Julio J. Rotemberg. MIT Press, pp. 73-103. 
[25] Kwon, H. \& Narita F. \& Machiko N. (2015). "Resource Reallocation and Zombie Lending in Japan in the 1990s," Review of Economic Dynamics, 18(4), pp. 709-732.

[26] Midrigan, V., \& Xu, D. (2014). "Finance and Misallocation: Evidence from Plant Level Data". American Economic Review, 104(2), pp. 422-458.

[27] Oberfield, E. (2013)."Productivity and misallocation during a crisis: Evidence from the Chilean crisis of 1982". Review of Economic Dynamics, 16(1), pp. 100-119.

[28] Petersen, M. \& Rajan R.G. (1994). "The Benefits of Lending Relationships: Evidence from Small Business Data". Journal of Finance, 49, pp. 3-37.

[29] Petersen, M. \& Rajan R.G. (1997). "Trade Credit: Some Theories and Evidence". Review of Financial Studies, 10(3), pp. 661-691.

[30] Pratap, S., \& Urrutia, C. (2012). "Financial frictions and total factor productivity: Accounting for the real effects of financial crises". Review of Economic Dynamics, 15(3), pp. 336-358.

[31] Restuccia, D., \& Rogerson, R. (2008). "Policy distortions and aggregate productivity with heterogeneous establishments". Review of Economic Dynamics, 11(4), pp. 707-720.

[32] Sandleris, G. \& Wright, M.L.J. (2014). "The Costs of Financial Crises": Resource Misallocation. Productivity and Welfare in the 2001 Argentine Crisis". Scandinavian Journal of Economics, 116(1), pp. $87-127$.

[33] Solow, R.M. (1957)." Technical Change and the Aggregate Production Function". Review of Economics and Statistics, 39, pp. 312-320. 


\section{A Appendix}

\section{A.1 Data Definitions}

\section{A.1.1 From Inegi's Encuesta Industrial Anual (EIA)}

The following variables, except for the capital stock that we construct, are available yearly and summed across all firms within each sector.

Gross Output is defined as the value of all production. This was cross-checked against an alternative value of gross output, namely the value of sales of the establishment plus change in inventories of finished goods.

Intermediate Goods are defined as the sum of expenditures on raw materials, packaging, fuels and energy.

Value Added is computed as gross output less intermediate goods.

Wage Bill includes all salaries and compensations to workers.

Labor is the sum of all male and female personnel employed directly and indirectly by the establishment. The latter includes labor provided by independent contractors.

Investment includes all purchases of investment goods, including structures and equipment. Real investment is obtained deflating nominal investment by the manufacturing PPI index.

Depreciation refers to all depreciation allowances. The depreciation rate is obtained dividing depreciation by the total value of assets, also obtained from the EIA dataset.

Capital Stock is constructed using the perpetual inventory method. We use initial real investment and a steady-state assumption to calculate the initial capital stock. We then update the real capital stock using investment flows and the sector specific depreciation rate. The nominal capital stock is obtained multiplying the real capital stock by the manufacturing PPI index.

\section{A.1.2 From CNBV's Credit Registry (R04)}

The $\mathrm{R} 04 \mathrm{C}$ variables are gathered at a monthly frequency. To make them compatible with the EIA variables, we aggregate financial data to the annual level.

Credit flow is constructed as the debt outstanding on all new loans (i.e. loans with dates of disbursement in the month in which the data is collected) to all firms in a particular sector. We only consider new short term loans, maturing in a period of 12 months or less. We sum the resulting flows for all months in a year to aggregate them at an annual frequency

Interest rate refers to the average real interest rates reported for all short term new loans to a particular sector. The average is weighted by the size of the loan in the total credit flow to this sector in the corresponding period. After aggregating it to an annual frequency, we construct the real interest rate by substracting from the nominal rate the change in the producer price index for manufacturing from the previous to the current years. 


\section{A.1.3 Matching EIA and R04C Sectoral Classifications}

In the R04C dataset, the sector of economic activity at the loan level from December 2001 to June 2009 is classified according to an internal CNBV classification. The data for the period July 2009 to July 2012, like that of the EIA, is classified according to the more standard NAICS 2007. To map the earlier R04 data into the NAICS 2007 classification we need a crosswalk that tells us how to reclassify each category.

The credit data we have was provided by the CNBV. We did not receive the disaggregated data which contains each particular credit issued during the December 2001-July 2012 period but were given the disaggregated (and anonymized) data for the period January 2009-December 2009. This data is especially useful for our purpose since it contains individual credit data for 6 months before and after the classification system changed. We used this data to build the crosswalk using a revealed reclassification method in which we make the mapping among both classifications by observing where each credit was originally classified and were it was reclassified once the classification system changed between June and July 2009.

We build a crosswalk by observing the reclassifications that actually took place in the data. The reason for building the crosswalk in this way instead of in a more arbitrary manner is that here we can take into account what actually happened and, in some sense, try to extract the crosswalk that was used when the reclassification was made and which is not available to us.

There are 1066 categories in the R04 data while there are 598 categories at the 5-digit level in the NAICS 2007 data. This means that in order to do a complete mapping, several R04C categories might be mapped into the same NAICS 2007 category. An additional problem is that the crosswalk we observe from the data is not deterministic in the sense that each credit in the $\mathrm{R} 04 \mathrm{C}$ is not always reclassified to the same NAICS 2007 category, rather the credits in each R04C category are reclassified into a small subset of NAICS 2007 categories (and to some more often than to others). Given this second problem we built a probabilistic crosswalk which lets us know into which categories we have to reclassify each R04C category and also tells us exactly how much we have to put into each.

As a brief illustrative example suppose we want to know how to reclassify the data from category 100000 in the R04C to the NAICS 2007. Suppose that in the disaggregated data we have 10 different credits classified to category 100000 between January and June 2009. Next suppose we see that once the reclassification takes place, we observe that 5 of these credits were reclassified during July and December 2009 into NAICS 2007 category 11111, 4 were reclassified to category 11112 and only 1 was reclassified into 11113. Then, the crosswalk would tell us that the data in category 100000 of the R04C should be distributed among categories 11111, 11112 and 11113 of the NAICS 2007 and the weights should be $50 \%, 40 \%$ and $10 \%$ respectively.

As mentioned previously the R04C data has 1066 categories, but when building the probabilistic crosswalk we were only able to map 995 of them. The remaining 71 categories were not mapped in this way because there were no credit observations in the disaggregated data that were originally classified into these categories and then reclassified to another in the NAICS 2007 (this happens if we have no credit observations for one of the 71 categories at all or if we only have them for the period January-June 2009). Fortunately we were able to use the catalog of the R04C to match 32 of the missing 71 categories into the NAICS 2007. To do this we matched them to the category whose name seemed more appropriate. For these 32 categories the crosswalk is deterministic as they were assigned fully to a single NAICS 2007 category. The remaining 39 categories in the R04 were not matched because they are missing in the catalog. 


\section{A.2 Solving for Aggregate TFP as a Function of Distortions}

Replacing the first order conditions for profit maximiation in each sector $i$ :

$$
\frac{K^{i}}{Y^{i}}=\frac{\alpha^{i} \varepsilon^{i}}{\theta_{K}^{i}}\left(\frac{p^{i}}{r}\right) \quad \frac{L^{i}}{Y^{i}}=\frac{\left(1-\alpha^{i}\right) \varepsilon^{i}}{\theta_{L}^{i}}\left(\frac{p^{i}}{w}\right) \quad \frac{M^{i}}{Y^{i}}=\frac{1-\varepsilon^{i}}{\theta_{M}^{i}}\left(\frac{p^{i}}{p^{M}}\right)
$$

in the production function (1) and using the demand condition

$$
p^{i} Y^{i}=\omega^{i} p Y^{g}
$$

coming from the Cobb-Douglas aggregator (2), we can write gross output for each sector as

$$
Y^{i}=\omega^{i} \frac{A^{i}}{\varphi^{i}}\left[\varepsilon^{i}\left(\frac{\alpha^{i}}{r}\right)^{\alpha^{i}}\left(\frac{1-\alpha^{i}}{w}\right)^{1-\alpha^{i}}\right]^{\varepsilon^{i}}\left(\frac{1-\varepsilon^{i}}{\phi}\right)^{1-\varepsilon^{i}} Y^{g}
$$

defining the total distortion for sector $i$ as

$$
\varphi^{i} \equiv\left[\left(\theta_{K}^{i}\right)^{\alpha^{i}}\left(\theta_{L}^{i}\right)^{1-\alpha^{i}}\right]^{\varepsilon^{i}}\left(\theta_{M}^{i}\right)^{1-\varepsilon^{i}}
$$

using $p^{M}=\phi$ and normalizing $p=1$. Aggregating intermediate goods demand across sectors and using again first order conditions, we obtain

$$
\begin{gathered}
\sum_{i=1}^{n} M^{i}=\left(\sum_{i=1}^{n} \omega^{i} \frac{1-\varepsilon^{i}}{\theta_{M}^{i}}\right) \frac{Y^{g}}{\phi}=M \\
\sum_{i=1}^{n} K^{i}=\left(\sum_{i=1}^{n} \omega^{i} \frac{\alpha^{i} \varepsilon^{i}}{\theta_{K}^{i}}\right) \frac{Y^{g}}{r} \quad \sum_{i=1}^{n} L^{i}=\left(\sum_{i=1}^{n} \omega^{i} \frac{\left(1-\alpha^{i}\right) \varepsilon^{i}}{\theta_{L}^{i}}\right) \frac{Y^{g}}{w}
\end{gathered}
$$

Solving for factor prices and replacing back in (1), we obtain

$$
Y^{i}=\omega^{i} \frac{A^{i}}{\Omega^{i}}\left[\frac{\varepsilon^{i}}{\varepsilon}\left(\frac{\alpha^{i}}{\alpha} K\right)^{\alpha^{i}}\left(\frac{1-\alpha^{i}}{1-\alpha} L\right)^{1-\alpha^{i}}\right]^{\varepsilon^{i}}\left(\frac{1-\varepsilon^{i}}{1-\varepsilon} M\right)^{1-\varepsilon^{i}}
$$

with the redefined aggregate shares $\varepsilon=\sum_{i=1}^{n} \omega^{i} \varepsilon^{i}, \alpha=\frac{\sum_{i=1}^{n} \omega^{i} \alpha^{i} \varepsilon^{i}}{\varepsilon}$ and defining the relative distortion for sector $i$ as:

$$
\Omega^{i} \equiv\left[\frac{\left(\sum_{j=1}^{n} \omega^{j} \frac{\alpha^{j} \varepsilon^{j}}{\theta_{K}^{j}}\right)^{\alpha^{i}}\left(\sum_{j=1}^{n} \omega^{j} \frac{\left(1-\alpha^{j}\right) \varepsilon^{j}}{\theta_{L}^{j}}\right)^{1-\alpha^{i}}}{\varepsilon \alpha^{\alpha^{i}}(1-\alpha)^{1-\alpha^{i}}}\right]^{\varepsilon^{i}}\left(\frac{\sum_{j=1}^{n} \omega^{j} \frac{1-\varepsilon^{j}}{\theta_{M}^{j}}}{1-\varepsilon}\right)^{1-\varepsilon^{i}} \varphi^{i}
$$

Finally, replacing sectoral gross output (2) in the Cobb-Douglas aggregator (2) gives us the following expression for aggregate gross output

$$
Y^{g}=\prod_{i=1}^{n}\left(\omega^{i} \frac{A^{i}}{\Omega^{i}} \psi^{i}\right)^{\omega^{i}}\left[K^{\alpha} L^{1-\alpha}\right]^{\varepsilon} M^{1-\varepsilon}
$$

with $\psi^{i} \equiv\left[\frac{\varepsilon^{i}}{\varepsilon}\left(\frac{\alpha^{i}}{\alpha}\right)^{\alpha^{i}}\left(\frac{1-\alpha^{i}}{1-\alpha}\right)^{1-\alpha^{i}}\right]^{\varepsilon^{i}}\left(\frac{1-\varepsilon^{i}}{1-\varepsilon}\right)^{1-\varepsilon^{i}}$. Since $Y=Y^{g}-\phi M$, replacing intermediates we obtain aggregate value added as

$$
Y=\prod_{i=1}^{n}\left(\omega^{i} \frac{A^{i}}{\Omega^{i}} \psi^{i}\right)^{\frac{\omega^{i}}{\varepsilon}} \phi^{\frac{\varepsilon-1}{\varepsilon}}\left(1-\sum_{j=1}^{n} \omega^{j} \frac{1-\varepsilon^{j}}{\theta_{M}^{j}}\right)\left(\sum_{j=1}^{n} \omega^{j} \frac{1-\varepsilon^{j}}{\theta_{M}^{j}}\right)^{\frac{1-\varepsilon}{\varepsilon}} K^{\alpha} L^{1-\alpha}
$$


and aggregate TFP

$$
T F P \equiv \frac{Y}{K^{\alpha} L^{1-\alpha}}=\prod_{i=1}^{n}\left(\omega^{i} \frac{A^{i}}{\Phi^{i}} \psi^{i}\right)^{\frac{\omega^{i}}{\varepsilon}} \varepsilon\left(\frac{1-\varepsilon}{\phi}\right)^{\frac{1-\varepsilon}{\varepsilon}}
$$

defining now the adjusted relative distortion for sector $i$ as

$$
\begin{gathered}
\Phi^{i} \equiv\left[\frac{\varepsilon^{\varepsilon^{i}}(1-\varepsilon)^{1-\varepsilon^{i}}}{\left(1-\sum_{j=1}^{n} \omega^{j} \frac{1-\varepsilon^{j}}{\theta_{M}^{j}}\right)^{\varepsilon^{i}}\left(\sum_{j=1}^{n} \omega^{j} \frac{1-\varepsilon^{j}}{\theta_{M}^{j}}\right)^{1-\varepsilon^{i}}}\right] \Omega^{i} \\
=\left[\frac{\varepsilon\left(\sum_{j=1}^{n} \omega^{j}\left(\frac{\alpha^{j} \varepsilon^{j}}{\alpha \varepsilon}\right) \frac{1}{\theta_{K}^{j}}\right)^{\alpha^{i}}\left(\sum_{j=1}^{n} \omega^{j}\left(\frac{\left(1-\alpha^{j}\right) \varepsilon^{j}}{(1-\alpha) \varepsilon}\right) \frac{1}{\theta_{L}^{j}}\right)^{1-\alpha^{i}}}{1-\sum_{j=1}^{n} \omega^{j} \frac{1-\varepsilon^{j}}{\theta_{M}^{j}}}\right]^{\varepsilon^{i}} \varphi^{i}
\end{gathered}
$$

or, substituting for the total distortions $\varphi^{i}$ and simplifying,

$$
\Phi^{i}=\frac{\left[\varepsilon\left(\sum_{j=1}^{n} \omega^{j}\left(\frac{\alpha^{j} \varepsilon^{j}}{\alpha \varepsilon}\right) \frac{\theta_{K}^{i}}{\theta_{K}^{j}}\right)^{\alpha^{i}}\left(\sum_{j=1}^{n} \omega^{j} \frac{\left(1-\alpha^{j}\right) \varepsilon^{j}}{(1-\alpha) \varepsilon} \frac{\theta_{L}^{i}}{\theta_{L}^{j}}\right)^{1-\alpha^{i}}\right]^{\varepsilon^{i}}\left((1-\varepsilon) \sum_{j=1}^{n} \omega^{j}\left(\frac{1-\varepsilon^{j}}{1-\varepsilon}\right) \frac{\theta_{M}^{i}}{\theta_{M}^{j}}\right)^{1-\varepsilon^{i}}}{\left(1-\sum_{j=1}^{n} \omega^{j} \frac{1-\varepsilon^{j}}{\theta_{M}^{j}}\right)^{\varepsilon^{i}}\left(\sum_{j=1}^{n} \omega^{j} \frac{1-\varepsilon^{j}}{\theta_{M}^{j}}\right)^{1-\varepsilon^{i}}} .
$$

\section{A.3 Characterizing the Solution to the Firm's Problem with Financial Frictions}

Omitting the sector superscript, the Lagrangian for this problem is

$$
p Y-r K-(1+\iota+(1-\kappa) \rho)\left(w L+p^{M} M\right)+\lambda\left[\frac{\xi p Y}{1+\iota}-\kappa\left(w L+p^{M} M\right)\right]+\mu(1-\kappa)
$$

with

$$
Y=A\left[(K)^{\alpha}(L)^{1-\alpha}\right]^{\varepsilon}(M)^{1-\varepsilon} .
$$

where $\lambda$ is the multiplier of the borrowing constraint and $\mu$ the multplier of the restriction $\kappa \leq 1$. The first order conditions for this problem together with the complementary slackness conditions define the system

$$
\begin{aligned}
\alpha \varepsilon p \frac{Y}{K}\left(1+\frac{\lambda \xi}{1+\iota}\right) & =r \\
(1-\alpha) \varepsilon p \frac{Y}{L}\left(1+\frac{\lambda \xi}{1+\iota}\right) & =w[(1+\iota+(1-\kappa) \rho)+\kappa \lambda] \\
(1-\varepsilon) p \frac{Y}{M}\left(1+\frac{\lambda \xi}{1+\iota}\right) & =p^{M}[(1+\iota+(1-\kappa) \rho)+\kappa \lambda] \\
\left(w L+p^{M} M\right)(\rho-\lambda) & =\mu \\
\lambda\left[\frac{\xi p Y}{1+\iota}-\kappa\left(w L+p^{M} M\right)\right] & =0 \\
\mu(1-\kappa) & =0 .
\end{aligned}
$$

with $\lambda, \mu \geq 0$ and unknowns $K, L, M, \kappa, \lambda$ and $\mu$, given prices $w, r, p^{M}, \iota, \rho$ and output $Y$. Notice that with constant returns to scale the first three first order conditions are equivalent to the production function, 
so the level of output $Y$ is indetermined (obtained from the demand side of the economy).To solve for the multipliers, replace (8) and (9) in (11) to obtain

$$
\lambda\left\{\xi-\kappa\left[\frac{1+\iota+\lambda \xi}{(1+\iota+(1-\kappa) \rho)+\kappa \lambda}\right](1-\alpha \varepsilon)\right\}=0
$$

which means that

$$
\lambda=\max \left\{\frac{\kappa(1+\iota)(1-\alpha \varepsilon-\xi)-(1-\kappa) \xi(1+\iota+\rho)}{\kappa \xi \alpha \varepsilon}, 0\right\}
$$

Similarly, replacing (8) and (9) in (10)

$$
\mu=\max \left\{\left[\frac{1+\iota+\lambda \xi}{(1+\iota)[(1+\iota+(1-\kappa) \rho)+\kappa \lambda]}\right](1-\alpha \varepsilon) p Y(\rho-\lambda), 0\right\}
$$

These last two equations will allow as to characterize the different cases or corner solutions.

Case 1: $\lambda>0, \mu=0$ In the first case the borrowing constraint is binding, but $\kappa \leq 1$. Using (10), we obtain $\lambda=\rho$. From (13), it has to be the case that

$$
\frac{\kappa(1+\iota)(1-\alpha \varepsilon-\xi)-(1-\kappa) \xi(1+\iota+\rho)}{\alpha \varepsilon \kappa \xi}=\rho
$$

so that

$$
\kappa=\frac{(1+\iota+\rho) \xi}{(1+\iota+\rho \xi)(1-\alpha \varepsilon)}
$$

This can only be a solution only if $\kappa \leq 1$, this is, if

$$
\xi \leq \frac{(1-\alpha \varepsilon)(1+\iota)}{1+\iota+\alpha \varepsilon \rho}
$$

depending on parameter values.

Case 2: $\lambda>0, \mu>0$ In this case both constraints are binding, so $\kappa=1$. From (13) and (14), we must have

and

$$
\lambda=\frac{(1+\iota)(1-\alpha \varepsilon-\xi)}{\alpha \varepsilon \xi}
$$

$$
\mu=\left[\frac{1+\iota+\lambda \xi}{(1+\iota)(1+\iota+\lambda)}\right](1-\alpha \varepsilon) p Y(\rho-\lambda)
$$

To have $\lambda>0$ and $\mu>0$ simultaneously we then need

$$
\frac{(1+\iota)(1-\alpha \varepsilon)}{(1+\iota)+\alpha \varepsilon \rho}<\xi<1-\alpha \varepsilon
$$

again depending on parameter values.

Case 3: $\lambda=0, \mu>0$ In this case $\kappa=1$ but the borrowing constraint is not binding. From (14), we must have

$$
\mu=\left[\frac{1+\iota+\lambda \xi}{(1+\iota)(1+\iota+\lambda)}\right](1-\alpha \varepsilon) p Y \rho>0
$$

which is always satisfied. On the other hand, from (13), we must have

$$
\frac{(1+\iota)(1-\alpha \varepsilon-\xi)}{\alpha \varepsilon \xi} \leq 0
$$

or $1-\alpha \varepsilon \leq \xi$, depending on parameter values. 
Case 4: $\lambda=0, \mu=0 \quad$ Using equation (10), this would imply

$$
w L+p^{M} M=0,
$$

but that requires at least one negative price or quantity. Therefore, we rule it out.

In Summary We have three relevant cases depending on parameters, in particular on how tight the borrowing constraints is:

- For high tightness $\xi \leq \frac{(1-\alpha \varepsilon)(1+\iota)}{1+\iota+\alpha \varepsilon \rho}$, Case $1(\lambda>0, \mu=0)$ occurs.

- For intermediate tightness $\frac{(1-\alpha \varepsilon)(1+\iota)}{1+\iota+\alpha \varepsilon \rho}<\xi<1-\alpha \varepsilon$, Case $2(\lambda>0, \mu>0)$ occurs.

- For low tightness $\xi \geq 1-\alpha \varepsilon$, Case $3(\lambda=0, \mu>0)$ occurs.

Implications for Distortions Notice that, in general, from FOC (7) - (9) we map the wedges to capital, labor and intermediates to:

$$
\theta_{K}=\frac{1+\iota}{1+\iota+\lambda \xi} \quad \theta_{M}=\theta_{L}=\left(\frac{1+\iota}{1+\iota+\lambda \xi}\right)[1+\iota+(1-\kappa) \rho+\kappa \lambda]
$$

so that total distortions defined in defined in equation (3) can be written as

$$
\varphi=\frac{1+\iota}{1+\iota+\lambda \xi}[1+\iota+(1-\kappa) \rho+\kappa \lambda]^{1-\alpha \varepsilon}
$$

depending on $\kappa$ and the multiplier $\lambda$ (but not on $\mu$ ). Then, in the different cases:

- Case 1: Since $\lambda=\rho$, we obtain

$$
\varphi=\frac{1+\iota}{1+\iota+\rho \xi}[1+\iota+\rho]^{1-\alpha \varepsilon}
$$

- Case 2: Since $\kappa=1$ and $\lambda=\frac{(1+\iota)(1-\alpha \varepsilon-\xi)}{\xi \alpha \varepsilon}$, we obtain

$$
\varphi=(1+\iota)^{1-\alpha \varepsilon}\left(\frac{\alpha \varepsilon}{1-\xi}\right)^{\alpha \varepsilon}\left(\frac{1-\alpha \varepsilon}{\xi}\right)^{1-\alpha \varepsilon}
$$

- Case 3: Since $\kappa=1$ and $\lambda=0$, we obtain

$$
\varphi=(1+\iota)^{1-\alpha \varepsilon}
$$

